\title{
Dynamic Modeling and Control Characteristics of the Two-Modular HTR-PM Nuclear Plant
}

\author{
Zhe Dong, Yifei Pan, Maoxuan Song, Xiaojing Huang, Yujie Dong, and Zuoyi Zhang \\ Institute of Nuclear and New Energy Technology, Collaborative Innovation Centre of Advanced Nuclear Energy Technology, \\ Key Laboratory of Advanced Reactor Engineering and Safety of Ministry of Education, Tsinghua University, Beijing 100084, China
}

Correspondence should be addressed to Zhe Dong; dongzhe@mail.tsinghua.edu.cn

Received 5 December 2016; Revised 2 March 2017; Accepted 5 March 2017; Published 22 May 2017

Academic Editor: Enrico Zio

Copyright (C) 2017 Zhe Dong et al. This is an open access article distributed under the Creative Commons Attribution License, which permits unrestricted use, distribution, and reproduction in any medium, provided the original work is properly cited.

\begin{abstract}
The modular high temperature gas-cooled reactor (MHTGR) is a typical small modular reactor (SMR) with inherent safety feature. Due to its high reactor outlet coolant temperature, the MHTGR can be applied not only for electricity production but also as a heat source for industrial complexes. Through multimodular scheme, that is, the superheated steam flows produced by multiple MHTGR-based nuclear supplying system (NSSS) modules combined together to drive a common thermal load, the inherent safety feature of MHTGR is applicable to large-scale nuclear plants at any desired power ratings. Since the plant power control technique of traditional single-modular nuclear plants cannot be directly applied to the multimodular plants, it is necessary to develop the power control method of multimodular plants, where dynamical modeling, control design, and performance verification are three main aspects of developing plant control method. In this paper, the study in the power control for two-modular HTR-PM plant is summarized, and the verification results based on numerical simulation are given. The simulation results in the cases of plant power step and ramp show that the plant control characteristics are satisfactory.
\end{abstract}

\section{Introduction}

With comparison to burning fossil fuels, there is nearly no greenhouse gas emission in nuclear fission reaction. Thus, nuclear fission energy is a crucial clean energy for giving basis products such as electricity, fresh water, and process heat and for addressing the challenges associated with global climate and environmental impact $[1,2]$. Actually, nuclear energy may substitute the fossil in a centralized way and in a great amount with commercial availability and economic competitiveness [3]. After the successful development of small (tens of megawatts) light water reactors (LWRs) for propulsion by the US Navy, the commercial nuclear reactors began to be commissioned since the late 1950s. These early-stage nuclear reactors were the simply scaled up versions of the naval reactor with high power density [4]. Although the increase of the reactor size induced the economic competitiveness with those fossil plants, the complicated operational issues began to moderate the industry's confidence in the plant safety. More stringent safety requirements were then imposed, which induced a complex layering of redundant safety and auxiliary systems to the original simple LWRs. The escalation of plant complexity contributed to the rapidly increasing costs, licensing periods, and construction delays. However, the plant safety still cannot be guaranteed satisfactorily. After the severe nuclear accidents, that is, Three Mile Island, Chernobyl, and Fukushima, the safety issues of nuclear reactors have become much more significant than before. Thus, there should be a novel reactor technology providing a satisfactory tradeoff between safety and economics.

Small modular reactors (SMRs) are those nuclear fission reactors whose electrical output power is less than $300 \mathrm{MW}_{\mathrm{e}}$ [4-6]. Due to the low power density and large heat capacity, some SMRs even have the inherent safety feature which prevents SMRs from the hazards of core-melting, radiological release, and LOCA (Loss of Coolant Accident). With loadfollowing function, SMRs can be incorporated with renewable energy sources to build hybrid energy systems (HESs) having the virtues such as persistent power supply and free refueling $[1,2]$. By adopting multimodular operation strategy 


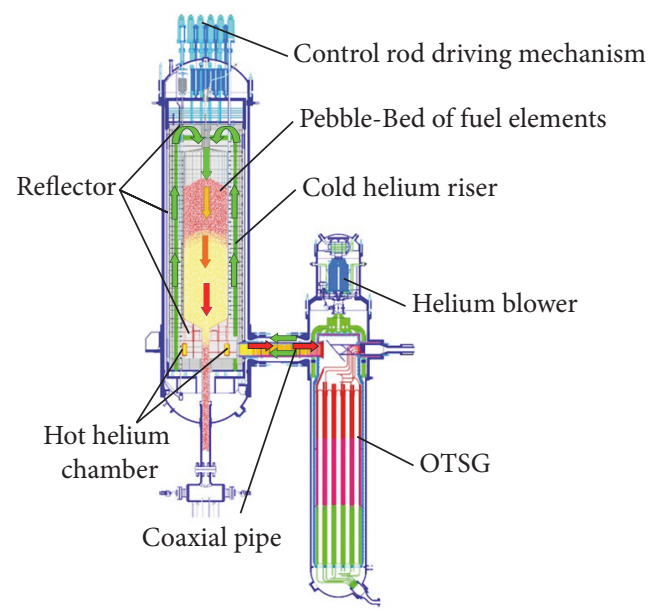

FIgURe 1: Composition of the MHTGR-based NSSS module.

[7], that is, multiple nuclear steam supplying system (NSSS) modules feeding steam to common thermal load equipment such as the turbine/generator set, the inherent safety feature of a SMR can be applicable to large-scale nuclear plants at any desired power ratings, which could be beneficial in providing electricity to remote areas without transmission or distribution infrastructure, in generating local power for a large population center and in being viable for specific applications such as heat sources for the industrial complexes. Furthermore, the SMRs can offer simpler, safer, and standardized modular design by being factory-built, requiring smaller initial capital investment, and having shorter construction period, and have been regarded by International Atomic Energy Agency (IAEA) as one of the active developing trends of nuclear energy.

Due to its inherent safety feature, the modular high temperature gas-cooled reactor (MHTGR, such as HTR-Module designed in Germany and MHTGR designed in US) has been seen as one of the best candidates for the nextgeneration nuclear plants. The MHTGR is a typical SMR which uses helium as coolant and graphite as moderator and structural material, and its inherent safety is determined by the low power density, strong negative temperature feedback effect, and slim reactor shape [8-10]. China began to study the MHTGR at the end of 1970 s, and a 10 MWth pebble-bed high temperature gas-cooled reactor HTR-10, which was designed by the Institute of Nuclear and New Energy Technology (INET) of Tsinghua University, achieved its criticality in December 2000 and full power in January 2003 [11]. Then, six safety demonstration tests were done on the HTR-10, which manifested its inherent safety and self-stabilizing features [12]. Based on the experience of the HTR-10 project, a high temperature gas-cooled reactor pebble-bed module (HTRPM) plant was then proposed, which consists of two pebblebed one-zone MHTGRs with combined $2 \times 250 \mathrm{MW}_{\text {th }}$ power and adopts the operation scheme of two NSSS modules driving one steam turbine $[13,14]$. Figure 1 shows that a NSSS module of the HTR-PM plant is composed of an MHTGR, a helically coiled once-through steam generator (OTSG), a primary helium blower, and some connecting pipes. Figure 2 illustrates a simplified flow diagram of the entire twomodular HTR-PM plant. The HTR-PM plant is now in the stage of plant construction and commissioning. By incorporating more MHTGR-based NSSS modules, more large-scale multimodular high temperature gas-cooled nuclear plant can be realized.

Satisfactory plant dynamic behavior is important for realizing load-following function and for further forming HESs with fossil or renewable energy sources, which is given by not only the open-loop dynamics but also the control strategy. There have been some promising results in dynamical modeling and control design for entire nuclear plants. In the field of plant modeling, Han gave a mathematical model of pressurized water reactors for thermal-hydraulic analysis [15]. Fazekas et al. proposed a simple dynamic model for the primary circuit in VVER plants for controller design purposes [16]. Dong et al. presented a lumped parameter dynamic model for control design and verification for the NSSS of the nuclear heating reactors (NHRs) [17]. With comparison to the abundant results in reactor power-level regulation such as the linear control, nonlinear control, and intelligent method [18-20], there are still less results in the field of entire nuclear plant control. Shtessel proposed a sliding-mode plant control and state-observation strategy for space nuclear energy system TOPAZ II [21]. Huang et al. gave a multi-input-multioutput (MIMO) fuzzy-adapted recursive sliding-mode plant controller for an advanced boiling water reactor (ABWR) nuclear power plant [22]. In order to achieve safe, stable, and efficient operation of the HTR-PM plant, it is necessary to give the lumped parameter model of the main plant dynamics and to propose proper plant control strategy. It is worth noting that, due to the two-modular scheme, there is much difference between the modeling and control of the HTR-PM plant and that of those single-modular nuclear plant.

In this paper, both the dynamical modeling and control design method for HTR-PM plant are first summarized or reviewed, the realization of feedback loops and control 


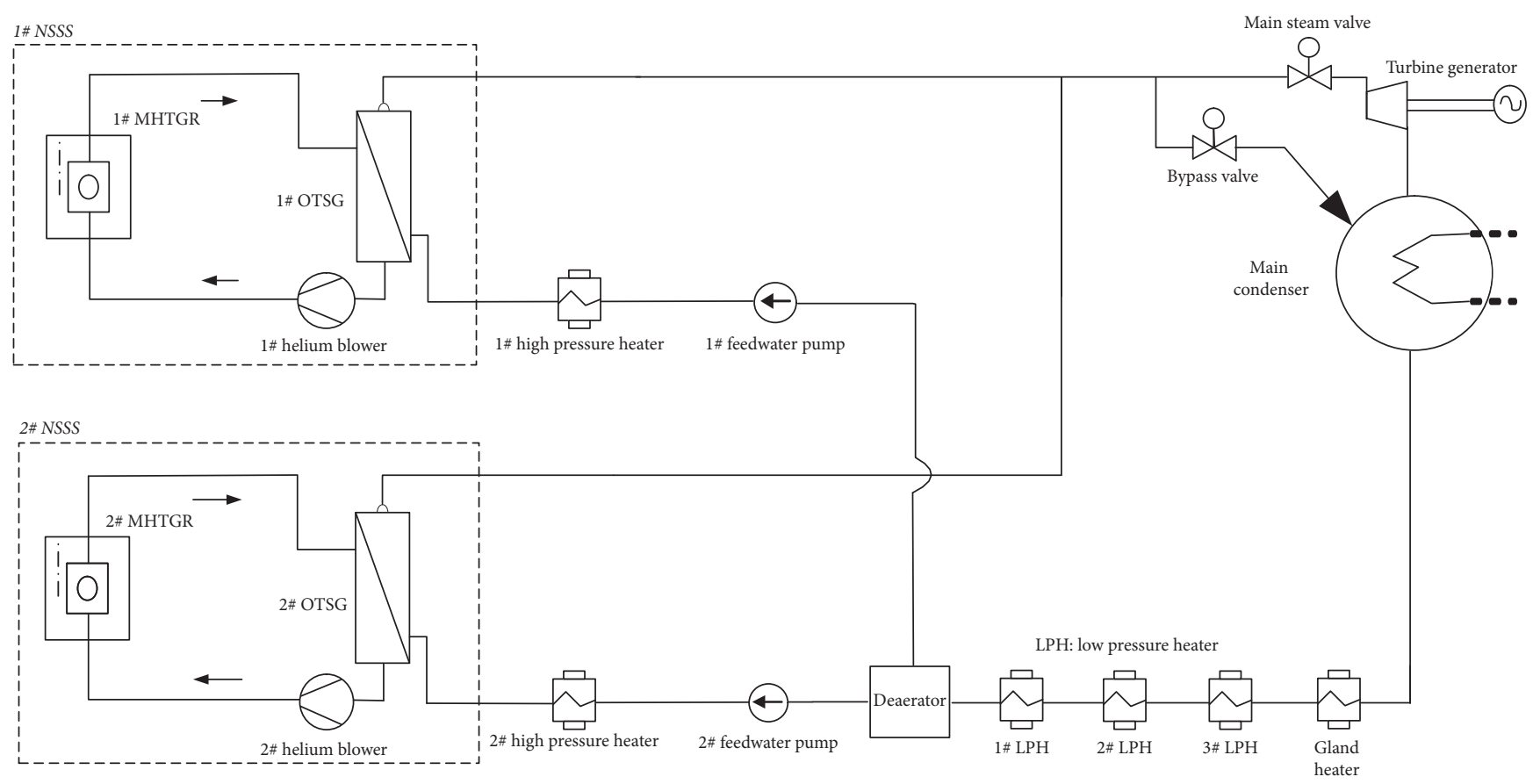

FIgURE 2: Simplified flow diagram for the HTR-PM plant.

laws are proposed, and then the verification results based upon numerical simulation are given, which shows the main transient performance of the HTR-PM plant is satisfactory for building HESs with the renewables.

\section{Dynamical Modeling}

In this section, the main parts of dynamic model of the HTRPM plant, that is, the pebble-bed one-zone MHTGR, OTSG, fluid flow network (FFN) of the common secondary-loop system, and turbine/generator unit, are summarized from [2326]. This model is proposed for control system design and verification, whose parameters are determined by the data collected from physical and thermal-hydraulic design.

2.1. MHTGR. From Figure 1, the cold helium enters the primary blower where it is pressurized before flowing into the cold gas duct. Then, the cold helium gets into the channels (called riser) inside the side reflector from bottom to top and passes through the pebble-bed (called downcomer) from top to bottom where it is heated to a high temperature about $750^{\circ} \mathrm{C}$. The hot helium leaves the hot gas chamber inside the bottom reflector and flows into the OTSG primary side where it transfers the heat to the secondary feedwater. To guarantee the inherent safety feature, the MHTGR of the HTR-PM plant has a slim core shape. Relative to using a single node [23], it is more proper to divide the reactor core into $N$ nodes along the axial direction [24]. The nodalization is shown in Figure 3, where the riser is some tubes in the side reflector through which helium can flow upward to the upper entry of the pebble-bed, and the downcomer is the volume gap among the fuel elements inside the pebble-bed through which helium can flow down. Moreover, the pressure loss of the primary helium flow is very small with comparison to the primary pressure and is omitted here.

2.1.1. Neutron Kinetics. The nodalized neutron kinetics can be written as [24]

$$
\begin{aligned}
\frac{\mathrm{d} n_{\mathrm{r}, 1}}{\mathrm{~d} t}= & \frac{\rho_{1}-\beta-\alpha_{1,1}}{\Lambda_{1}} n_{\mathrm{r}, 1}+\frac{1}{\Lambda_{1}} \alpha_{1,2} n_{\mathrm{r}, 2}+\sum_{k=1}^{6} \frac{\beta_{k}}{\Lambda_{1}} C_{\mathrm{r}, 1, k}, \\
\frac{\mathrm{d} n_{\mathrm{r}, i}}{\mathrm{~d} t}= & \frac{\rho_{i}-\beta-\alpha_{i, i}}{\Lambda_{i}} n_{\mathrm{r}, i} \\
& +\frac{1}{\Lambda_{i}}\left(\alpha_{i, i-1} n_{\mathrm{r}, i-1}+\alpha_{i, i+1} n_{\mathrm{r}, i+1}\right) \\
& +\sum_{k=1}^{6} \frac{\beta_{k}}{\Lambda_{i}} C_{\mathrm{r}, i, k}, \quad i=2, \ldots, N-1, \\
\frac{\mathrm{d} n_{\mathrm{r}, N}}{\mathrm{~d} t}= & \frac{\rho_{N}-\beta-\alpha_{N, N}}{\Lambda_{N}} n_{\mathrm{r}, N}+\frac{1}{\Lambda_{N}} \alpha_{N, N-1} n_{\mathrm{r}, N-1} \\
& +\sum_{k=1}^{6} \frac{\beta_{k}}{\Lambda_{N}} C_{\mathrm{r}, N, k}, \\
\frac{\mathrm{d} C_{\mathrm{r}, i, k}}{\mathrm{~d} t}= & \lambda_{k}\left(n_{\mathrm{r}, i}-C_{\mathrm{r}, i, k}\right), \\
& \quad i=1, \ldots, N, k=1,2, \ldots, 6,
\end{aligned}
$$




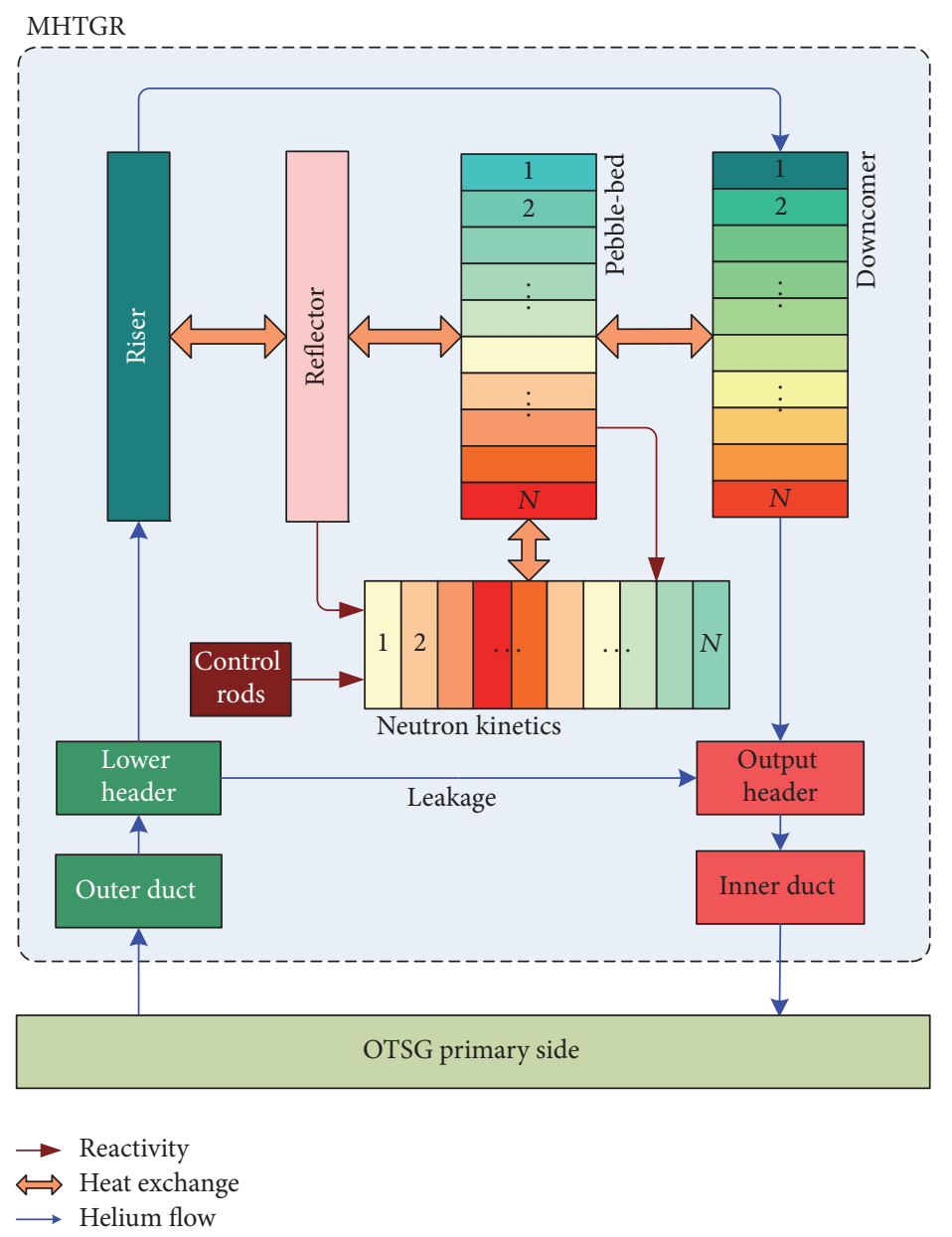

FIgURE 3: Nodalization of the MHTGR.

where $i=1, \ldots, N, n_{\mathrm{r}, i}$ is the relative neutron flux of the $i$ th node, $C_{\mathrm{r}, i, k}$ is the relative concentration of the $k$ th delayed neutron group of the $i$ th node, $\alpha_{i, i}$ and $\alpha_{i, i}\left(j=1, \ldots, N_{i}\right)$ are the coupling coefficients corresponding to the $i$ th node, $N_{i}$ is the number of adjacent nodes of the $i$ th node, $\Lambda_{i}$ is the prompt neutron lifetime in the $i$ th node, $\rho_{i}$ is the reactivity of the $i$ th node, $\beta$ is the fraction of all the delayed neutrons in all the nodes, and $\beta_{k}$ is the fraction of the $k$ th delayed neutron group in every node.

The nodal reactivity feedback is expressed as function of the nodal fuel temperature $T_{c, i}(i=1, \ldots, N)$ and temperature of the reflector $T_{\mathrm{r}}$. The total nodal reactivity is given as [24]

$$
\rho_{i}=\rho_{\mathrm{r}, i}+\left(\alpha_{\mathrm{f}, i}+\alpha_{\mathrm{m}, i}\right)\left(T_{\mathrm{c}, i}-T_{\mathrm{c} 0, i}\right)+\alpha_{\mathrm{r}}\left(T_{\mathrm{r}}-T_{\mathrm{r} 0}\right),
$$

where $\rho_{\mathrm{r}, i}$ is the nodal reactivity provided by the control rods, $\alpha_{\mathrm{f}, i}$ and $\alpha_{\mathrm{m}, i}$ are, respectively, the reactivity coefficients of the fuel and moderator inside node $i, \alpha_{\mathrm{r}}$ is the reactivity coefficient of the average reflector temperature, and $T_{\mathrm{c} 0, i}$ and $T_{\mathrm{r} 0}$ are, respectively, the initial temperature of the fuel inside node $i$ and that of the reflector. Since the reflector is very thick, and since the metal core support structure is cooled by the cold helium with its temperature no more than $250^{\circ} \mathrm{C}$, the reactivity feedback induced by the support structure is omitted here, which has been verified by the MHTGR physical and thermal-hydraulic design.

Moreover, it can be derived that [24]

$$
\begin{gathered}
\alpha_{i, j}=\left(\frac{n_{j 0}}{n_{i 0}}\right) \frac{D A}{v \Sigma_{\mathrm{f}, i} V d}, \\
j= \begin{cases}2, & i=1 \\
i-1, i+1, & i=2, \ldots, N-1 \\
N-1, & i=N,\end{cases} \\
\alpha_{i, i}= \begin{cases}\frac{D A}{v \sum_{\mathrm{f}, 2} V d}, & i=1, \\
\frac{D A}{v V d}\left(\frac{1}{\sum_{\mathrm{f}, i-1}}+\frac{1}{\sum_{\mathrm{f}, i+1}}\right), & i=2, \ldots, N-1, \\
\frac{D A}{v \sum_{\mathrm{f}, N-1} V d}, & i=N,\end{cases}
\end{gathered}
$$

where $A$ is the cross-sectional area of the active core region, $V$ is the volume of every node, $d$ is the height of every node, $v$ is the fission number, $\Sigma_{\mathrm{a}, i}$ and $\Sigma_{\mathrm{f}, i}(i=1, \ldots, N)$ are, 
respectively, the macroabsorption and fission cross sections in the $i$ th node.

\subsubsection{Thermal Hydraulics}

(1) Pebble-Bed. The thermal dynamics of ith node of the pebble-bed can be written as [24]

$$
\begin{aligned}
(1-\varepsilon) \rho_{\mathrm{c}, i} V C_{\mathrm{c}, i} \frac{\mathrm{d} T_{\mathrm{c}, i}}{\mathrm{~d} t}= & P_{0, i} n_{\mathrm{r}, i}-K_{\mathrm{d}, i} A_{\mathrm{d}, i}\left(T_{\mathrm{c}, i}-T_{\mathrm{d}, i}\right)-K_{\mathrm{cr}, i} A_{\mathrm{cr}, i}\left(T_{\mathrm{c}, i}-T_{\mathrm{r}}\right) \\
& + \begin{cases}-K_{\mathrm{c}, 1} A\left(T_{\mathrm{c}, 1}-T_{\mathrm{c}, 2}\right), & i=1, \\
-K_{\mathrm{c}, i} A\left(T_{\mathrm{c}, i}-T_{\mathrm{c}, i+1}\right)+K_{\mathrm{c}, i-1} A\left(T_{\mathrm{c}, i-1}-T_{\mathrm{c}, i}\right), & i=2, \ldots, N-1, \\
K_{\mathrm{c}, N-1} A\left(T_{\mathrm{c}, N-1}-T_{\mathrm{c}, N}\right), & i=N,\end{cases}
\end{aligned}
$$

where $\rho_{\mathrm{c}, i}, C_{\mathrm{c}, i}, T_{\mathrm{c}, i}$, and $P_{0, i}$ are, respectively, the density, specific heat, temperature, and rated power of fuel pile inside node $i, K_{\mathrm{d}, i}$ and $A_{\mathrm{d}, i}$ are, respectively, the heat transfer coefficient and heat transfer area between the fuel pile and helium inside node $i, T_{\mathrm{d}, i}$ is the temperature of the helium inside node $i, K_{\mathrm{cr}, i}$ and $A_{\mathrm{cr}, i}$ are, respectively, the heat transfer coefficient and heat transfer area between the fuel pile in node $i$ and the reflector, $T_{\mathrm{r}}$ is the temperature of the reflector, $K_{\mathrm{c}, i}$ $(i=1, \ldots, N-1)$ is the heat transfer coefficient between the fuel pile inside node $i$ and that inside node $i+1$, and $\varepsilon$ is the porosity of the pebble-bed.

(2) Reflector. To improve the heat capacity and to weaken the neutron leakage, the reflector of the MHTGR is very thick, which means that the thermal inertial of the reflector is so large that the dynamic response of the reflector is in different scale with that of the fuel elements and helium flow. Moreover, the side reflector is cooled by the cold helium flow injected into the reactor with a high speed. Therefore, for the simplicity of dynamic model, it is reasonable to regard the reflector as one nodal.

From Figure 3, there are two heat transfer processes with the reflector. This first one is the fission heat conducted from the fuel pile inside every node, which heats up the reflector. The second one is that the cold helium inside the riser cools down the reflector. The heat transfer about the reflector can be written as [24]

$$
\begin{aligned}
\rho_{\mathrm{r}} V_{\mathrm{r}} C_{\mathrm{r}} \frac{\mathrm{d} T_{\mathrm{r}}}{\mathrm{d} t}= & \sum_{i=1}^{N} K_{\mathrm{cr}, i} A_{\mathrm{cr}, i}\left(T_{\mathrm{c}, i}-T_{\mathrm{r}}\right) \\
& -K_{\mathrm{ur}} A_{\mathrm{ur}}\left(T_{\mathrm{r}}-T_{\mathrm{u}}\right)
\end{aligned}
$$

where $\rho_{\mathrm{r}}, V_{\mathrm{r}}$, and $C_{\mathrm{r}}$ are, respectively, the density, volume, and specific heat of the reflector, $K_{\mathrm{ur}}$ and $A_{\mathrm{ur}}$ are the heat transfer coefficient and heat transfer area between the reflector and the coolant in the riser, and $T_{\mathrm{u}}$ is the average coolant temperature inside the riser.

(3) Downcomer. The cold helium enters the downcomer from its upper entry and flows downward to cool the pebblebed. The heat is mainly transferred to the helium inside the downcomer, which can be described as [24]

$$
V_{i} \frac{\mathrm{d} \rho_{\mathrm{d}, i}}{\mathrm{~d} t}= \begin{cases}W_{\mathrm{u}}-W_{\mathrm{d}, 1}, & i=1, \\ W_{\mathrm{d}, i-1}-W_{\mathrm{d}, i}, & i=2, \ldots, N,\end{cases}
$$

$$
\begin{aligned}
\varepsilon V_{i} C_{\mathrm{p}} & \frac{\mathrm{d}\left(\rho_{\mathrm{d}, i} T_{\mathrm{d}, i}\right)}{\mathrm{d} t} \\
= & K_{\mathrm{d}, i} A_{\mathrm{d}, i}\left(T_{\mathrm{c}, i}-T_{\mathrm{d}, i}\right) \\
& + \begin{cases}C_{\mathrm{p}}\left(W_{\mathrm{u}} T_{\mathrm{u}}-W_{\mathrm{d}, 1} T_{\mathrm{d}, 1}\right), & i=1, \\
C_{\mathrm{p}}\left(W_{\mathrm{d}, i-1} T_{\mathrm{d}, i-1}-W_{\mathrm{d}, i} T_{\mathrm{d}, i}\right), & i=2, \ldots, N,\end{cases}
\end{aligned}
$$

where $\rho_{\mathrm{d}, i}$ and $W_{\mathrm{d}, i}$ are, respectively, the density and flowrate of the helium inside node $i$ of the downcomer and $C_{p}$ is the helium specific heat at constant pressure. Then, substitute (6), the thermodynamics of the helium in the downcomer can be written as [24]

$$
\begin{aligned}
\varepsilon V_{i} \rho_{\mathrm{d}, i} & C_{\mathrm{p}} \frac{\mathrm{d} T_{\mathrm{d}, i}}{\mathrm{~d} t} \\
= & K_{\mathrm{d}, i} A_{\mathrm{d}, i}\left(T_{\mathrm{c}, i}-T_{\mathrm{d}, i}\right) \\
& + \begin{cases}C_{\mathrm{p}} W_{\mathrm{u}}\left(T_{\mathrm{u}}-T_{\mathrm{d}, 1}\right), & i=1, \\
C_{\mathrm{p}} W_{\mathrm{d}, i-1}\left(T_{\mathrm{d}, i-1}-T_{\mathrm{d}, i}\right), & i=2, \ldots, N .\end{cases}
\end{aligned}
$$

(4) Riser. In the channels of the riser, the cold helium flows upward to cool the reflector, and the heat transfer process can be described by $[23,24]$

$$
\begin{aligned}
V_{\mathrm{u}} \frac{\mathrm{d} \rho_{\mathrm{u}}}{\mathrm{d} t}= & (1-\kappa) W_{\mathrm{lh}}-W_{\mathrm{u}}, \\
V_{\mathrm{u}} C_{\mathrm{p}} \frac{\mathrm{d}\left(\rho_{\mathrm{u}} T_{\mathrm{u}}\right)}{\mathrm{d} t}= & C_{\mathrm{p}}\left[(1-\kappa) W_{\mathrm{lh}} T_{\mathrm{lh}}-W_{\mathrm{u}} T_{\mathrm{u}}\right] \\
& +K_{\mathrm{ur}} A_{\mathrm{ur}}\left(T_{\mathrm{r}}-T_{\mathrm{u}}\right),
\end{aligned}
$$

where $\rho_{\mathrm{u}}, W_{\mathrm{u}}$, and $T_{\mathrm{u}}$ are, respectively, the density, flowrate, and temperature of the helium inside the riser, $W_{\mathrm{lh}}$ and $T_{\mathrm{lh}}$ are, respectively, the flowrate and temperature of the helium inside the lower header, and $\kappa$ is the leakage ration of the lower header. Substitute (8), the thermodynamics of the helium inside the riser can be written as

$$
\begin{aligned}
V_{\mathrm{u}} \rho_{\mathrm{u}} C_{\mathrm{p}} \frac{\mathrm{d} T_{\mathrm{u}}}{\mathrm{d} t}= & C_{\mathrm{p}}(1-\kappa) W_{\mathrm{lh}}\left(T_{\mathrm{lh}}-T_{\mathrm{u}}\right) \\
& +K_{\mathrm{ur}} A_{\mathrm{ur}}\left(T_{\mathrm{r}}-T_{\mathrm{u}}\right) .
\end{aligned}
$$




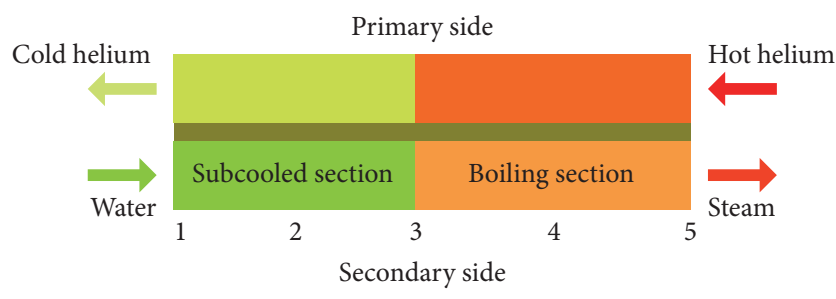

FIgURE 4: Nodalization scheme of the OTSG.

(5) Lower Header. The lower header is assumed to be a well-mixed chamber which has no heat exchange with the environment, and the thermodynamics corresponding to the lower header can be expressed as $[23,24]$

$$
V_{\mathrm{lh}} \rho_{\mathrm{lh}} \frac{\mathrm{d} T_{\mathrm{lh}}}{\mathrm{d} t}=W_{\mathrm{lh}}\left(T_{\mathrm{in}}-T_{\mathrm{lh}}\right),
$$

where $T_{\text {in }}$ is the temperature of the inlet cold helium, $\rho_{\mathrm{lh}}$, $W_{\mathrm{lh}}$, and $T_{\mathrm{lh}}$ are, respectively, the density, flowrate, and temperature of the helium inside the lower header, and $V_{\mathrm{lh}}$ is the volume of the low header.

(6) Outlet Header. The output header is assumed to be a wellmixed chamber, and its dynamics can be given as $[23,24]$

$$
V_{\mathrm{oh}} \rho_{\mathrm{oh}} \frac{\mathrm{d} T_{\mathrm{oh}}}{\mathrm{d} t}=\kappa W_{\mathrm{lh}}\left(T_{\mathrm{lh}}-T_{\mathrm{oh}}\right)+W_{\mathrm{d}, N}\left(T_{\mathrm{d}, 10}-T_{\mathrm{oh}}\right),
$$

where $\rho_{\mathrm{oh}}, W_{\mathrm{lh}}$, and $T_{\mathrm{oh}}$ are, respectively, the density, flowrate, and temperature of the helium inside the outlet header and $V_{\mathrm{oh}}$ is the volume of the outlet header.

2.1.3. MHTGR Dynamics. The dynamic model of MHTGR is composed of neutron kinetics determined by (1)-(3) as well as thermal hydraulics given by (4), (5), (7), and (9)-(11). The dynamic behavior of this MHTGR model can be influenced by nodal number $N$, and an improper nodal number leads to the fluctuation of the responses. Actually, this model is only utilized for control design and verification and is not for physical and thermal-hydraulic design. The nodal numbers are determined by comparing the response of this model with that of the model for physical and thermal-hydraulic design. When the error between responses is satisfactorily small, the corresponding nodal number is suitable. Here, the nodal number $N$ is chosen to be 10 . Based on the simulation results to be given in Section 4, it will be seen that there is no numerical fluctuation in the responses, and all the transience is determined by powerlevel maneuver which show that the nodal number is properly selected.

Since the dynamic model in this paper is tuned based upon the comparison with the model for reactor physical and thermal-hydraulic design, the stability of this model is also guaranteed by the model for reactor design. Moreover, it was shown in [27] that the MHTGR is open-loop globally asymptotically stable, and by the use of the shifted-ectropybased self-stability analysis method given in [27], it can be shown that the model coupled by neutron kinetics and thermal hydraulics are open-loop globally asymptotically stable.

2.2. OTSG. Since the OTSG can provide superheated steam which does not satisfy the one-to-one map from pressure to temperature, the OTSG is more proper for building multiSMR-based nuclear plants. Therefore, the dynamic model of the OTSG is very crucial for studying behavior of the SMR-based plant and also for verifying the operation and control strategies. In this section, a moving-boundary model [25] is introduced for describing OTSG dynamics in the cases of generating saturated and superheated steam [26]. The nodalization of the OTSG is given in Figure 4.

2.2.1. Secondary Side. The dynamics of the OTSG secondary side is given by both the thermodynamics and pressure drops of the secondary fluid flow.

(1) Thermodynamics. The thermodynamics of the secondary side can be given by the following vector-valued nonlinear differential equation [26]:

$$
\mathbf{E}_{\mathrm{s}}\left(\mathbf{x}_{\mathrm{s}}\right) \frac{\mathrm{d} \mathbf{x}_{\mathrm{s}}}{\mathrm{d} t}=\mathbf{f}_{\mathrm{s}}\left(\mathbf{x}_{\mathrm{s}}, \mathbf{u}_{\mathrm{s}}\right),
$$

where

$$
\begin{aligned}
& \mathbf{x}_{\mathrm{s}}=\left[\begin{array}{llll}
l_{13} & h_{\mathrm{s} 5} & h_{\mathrm{s} 1} & G_{\mathrm{s} 3}
\end{array}\right]^{\mathrm{T}}, \\
& \mathbf{u}_{\mathrm{s}}=\left[\begin{array}{llll}
G_{\mathrm{s} 1} & h_{\mathrm{fw}} & Q_{\mathrm{s} 2} & Q_{\mathrm{s} 4}
\end{array}\right]^{\mathrm{T}}, \\
& \mathbf{E}_{\mathrm{s}}\left(\mathbf{x}_{\mathrm{s}}\right)=\left[\begin{array}{cccc}
E_{\mathrm{s} 11}\left(\mathbf{x}_{\mathrm{s}}\right) & 0 & \frac{1}{2} \rho_{\mathrm{s} 2} l_{13} & E_{\mathrm{s} 14}\left(\mathbf{x}_{\mathrm{s}}\right) \\
E_{\mathrm{s} 21}\left(\mathbf{x}_{\mathrm{s}}\right) & \frac{1}{2} \rho_{\mathrm{s} 4} l_{35} & 0 & E_{\mathrm{s} 24}\left(\mathbf{x}_{\mathrm{s}}\right) \\
0 & 0 & \tau_{\mathrm{H}} & 0 \\
0 & 0 & 0 & \tau_{\mathrm{G}}
\end{array}\right], \\
& E_{\mathrm{s} 11}\left(\mathbf{x}_{\mathrm{s}}\right)=\frac{1}{2}\left[\rho_{\mathrm{s} 3}\left(h_{\mathrm{s} 1}-h_{\mathrm{s} 3}\right)+\left(P_{\mathrm{s} 3}-P_{\mathrm{s} 1}\right)+l_{13}\left(1-\left.\rho_{\mathrm{s} 2} \frac{\partial h_{\mathrm{s} 3}}{\partial P_{\mathrm{s} 3}}\right|_{P_{\mathrm{s} 3}}\right)\left(\rho_{\mathrm{s} 2} g \sin \theta+F_{\mathrm{s} 2} \frac{G_{\mathrm{s} 2}^{2}}{A_{\mathrm{s} 2}^{2}}\right)\right],
\end{aligned}
$$




$$
\begin{aligned}
& E_{\mathrm{s} 14}\left(\mathbf{x}_{\mathrm{s}}\right)=\frac{F_{\mathrm{s} 2} G_{\mathrm{s} 2}^{2} l_{13}^{2}}{2 A_{\mathrm{s} 2}^{2}}\left(1-\left.\rho_{\mathrm{s} 2} \frac{\partial h_{\mathrm{s} 3}}{\partial P_{\mathrm{s} 3}}\right|_{P_{\mathrm{s} 3}}\right), \\
& E_{\mathrm{s} 21}\left(\mathbf{x}_{\mathrm{s}}\right) \\
& \quad=\frac{1}{2}\left\{\rho_{\mathrm{s} 3}\left(h_{\mathrm{s} 3}-h_{\mathrm{s} 5}\right)+\left(P_{\mathrm{s} 5}-P_{\mathrm{s} 3}\right)+l_{35}\left[\left(2-\left.\rho_{\mathrm{s} 4} \frac{\partial h_{\mathrm{s} 3}}{\partial P_{\mathrm{s} 3}}\right|_{P_{\mathrm{s} 3}}\right)\left(\rho_{\mathrm{s} 2} g \sin \theta+F_{\mathrm{s} 2} \frac{G_{\mathrm{s} 2}^{2}}{A_{\mathrm{s} 2}^{2}}\right)-\left(\rho_{\mathrm{s} 4} g \sin \theta+F_{\mathrm{s} 4} \frac{G_{\mathrm{s} 4}^{2}}{A_{\mathrm{s} 4}^{2}}\right)\right]\right\}, \\
& E_{\mathrm{s} 24}\left(\mathbf{x}_{\mathrm{s}}\right)=l_{35}\left[\left(1-\left.\frac{1}{2} \rho_{\mathrm{s} 4} \frac{\partial h_{\mathrm{s} 3}}{\partial P_{\mathrm{s} 3}}\right|_{P_{\mathrm{s} 3}}\right) \frac{F_{\mathrm{s} 2} G_{\mathrm{s} 2} l_{13}}{A_{\mathrm{s} 2}^{2}}+\frac{2 F_{\mathrm{s} 4} G_{\mathrm{s} 4} l_{13}}{A_{\mathrm{s} 2}^{2}}\right], \\
& \mathbf{f}_{\mathrm{s}}\left(\mathbf{x}_{\mathrm{s}}, \mathbf{u}_{\mathrm{s}}\right)=\left[\frac{Q_{\mathrm{s} 2}}{A_{\mathrm{s} 2}}+\frac{1}{2}\left(\frac{G_{\mathrm{s} 1}}{A_{\mathrm{s} 1}}+\frac{G_{\mathrm{s} 3}}{A_{\mathrm{s} 3}}\right)\left(h_{\mathrm{s} 1}-h_{\mathrm{s} 3}\right) \frac{Q_{\mathrm{s} 4}+G_{\mathrm{s} 4}\left(h_{\mathrm{s} 3}-h_{\mathrm{s} 5}\right)}{A_{\mathrm{s} 4}} \frac{h_{\mathrm{fw}}-h_{\mathrm{s} 1}}{\tau_{\mathrm{H}}} \frac{G_{\mathrm{s} 1}-G_{\mathrm{s} 3}}{\tau_{\mathrm{G}}}\right]^{\mathrm{T}},
\end{aligned}
$$

$g$ is the gravitational acceleration $\left(\mathrm{N} \cdot \mathrm{m} / \mathrm{s}^{2}\right)$, both $\tau_{\mathrm{G}}$ and $\tau_{\mathrm{H}}$ are given positive constants denoting inertial effect, $h_{\mathrm{fw}}$ is the enthalpy per unit mass $(\mathrm{J} / \mathrm{kg})$ of the feedwater flow, $l_{i j}$ $(i, j=1, \ldots, 5$ and $i<j)$ is the length between points $i$ and $j$ in Figure 4 , and $\rho_{s i}, G_{s i}, h_{\mathrm{s} i} Q_{\mathrm{s} i}$, and $A_{\mathrm{s} i}$ are, respectively, the flow density $\left(\mathrm{kg} / \mathrm{m}^{3}\right)$, flowrate $(\mathrm{kg} / \mathrm{s})$, enthalpy per unit mass $(\mathrm{J} / \mathrm{kg})$, heat flux from the primary side, and cross section $\left(\mathrm{m}^{2}\right)$ of node $i$ of the secondary side. Here, $l_{13}$ is the length of the subcooled section, $l_{35}$ is that of the boiling section, and $h_{1 \mathrm{~s}}$ is specific enthalpy of the feedwater. Due to the high speed of the steam flow, it is assumed that $G_{\mathrm{s} 3}=G_{\mathrm{s} 4}=G_{\mathrm{s} 5}$.

(2) Pressure Drops. The pressure drop of the fluid flow in the OTSG secondary side cannot be omitted, and the pressure of each node is given by [26]

$$
\begin{aligned}
& P_{\mathrm{s} 3}=P_{\mathrm{s} 1}-\rho_{\mathrm{s} 2} g l_{13} \sin \theta-F_{\mathrm{s} 2} l_{13} G_{\mathrm{s} 2}^{2}, \\
& P_{\mathrm{s} 5}=P_{\mathrm{s} 3}-\rho_{\mathrm{s} 4} g l_{35} \sin \theta-F_{\mathrm{s} 4} l_{35} G_{\mathrm{s} 4}^{2}, \\
& P_{\mathrm{s} 4}=\frac{\left(P_{\mathrm{s} 3}+P_{\mathrm{s} 5}\right)}{2}, \\
& P_{\mathrm{s} 2}=\frac{\left(P_{\mathrm{s} 1}+P_{\mathrm{s} 3}\right)}{2},
\end{aligned}
$$

where $\theta$ is the helically coiled angle of the tubes, $F_{s i}(i=2,4)$ is the friction factor of the two sections, and $P_{\mathrm{s} 1}$ is the feedwater pressure.

2.2.2. Tube Wall. There is no flow inside the metal tube wall between the primary and secondary sides, and the dynamics of the tube wall are determined by its thermodynamics, which can be expressed as [26]

$$
\begin{aligned}
& \frac{\mathrm{d} T_{\mathrm{m} 2}}{\mathrm{~d} t}=\frac{Q_{\mathrm{p} 2}-Q_{\mathrm{s} 2}}{C_{\mathrm{m}} \rho_{\mathrm{m}} A_{\mathrm{m} 2} l_{13}}+\frac{T_{\mathrm{m} 4}-T_{\mathrm{m} 2}}{l_{15}} \frac{\mathrm{d} l_{13}}{\mathrm{~d} t}, \\
& \frac{\mathrm{d} T_{\mathrm{m} 4}}{\mathrm{~d} t}=\frac{Q_{\mathrm{p} 4}-Q_{\mathrm{s} 4}}{C_{\mathrm{m}} \rho_{\mathrm{m}} A_{\mathrm{m} 4} l_{35}}+\frac{T_{\mathrm{m} 4}-T_{\mathrm{m} 2}}{l_{15}} \frac{\mathrm{d} l_{13}}{\mathrm{~d} t},
\end{aligned}
$$

where $Q_{p 2}$ and $Q_{p 4}$ are, respectively, the heat flux from the primary helium flow to tube wall in the subcooled and boiling sections.

2.2.3. Primary Side. Since velocity of the primary helium flow is much higher than that of the two-phase flow inside the secondary side, the energy and temperature relationship of the primary side can be given by the following algebraic equation [26]:

$$
\mathbf{A}_{\mathrm{p}}\left(\mathbf{x}_{\mathrm{s}}\right) \mathbf{x}_{\mathrm{p}}=\mathbf{b}_{\mathrm{p}}\left(\mathbf{x}_{\mathrm{m}}, \mathbf{x}_{\mathrm{p}}\right)
$$

where

$$
\begin{aligned}
& \mathbf{x}_{\mathrm{p}}=\left[\begin{array}{llll}
T_{\mathrm{p} 1} & T_{\mathrm{p} 2} & T_{\mathrm{p} 3} & T_{\mathrm{p} 4}
\end{array}\right]^{\mathrm{T}}, \\
& \mathbf{A}_{\mathrm{p}}\left(\mathbf{x}_{\mathrm{m}}\right)=\left[\begin{array}{cccc}
1 & -2 & 1 & 0 \\
0 & l_{35} & -l_{15} & l_{13} \\
-C_{\mathrm{p}} G_{\mathrm{p}} & -K_{\mathrm{p} 2} l_{13} & C_{\mathrm{p}} G_{\mathrm{p}} & 0 \\
0 & 0 & -C_{\mathrm{p}} G_{\mathrm{p}} & -K_{\mathrm{p} 4} l_{35}
\end{array}\right], \\
& \mathbf{b}_{\mathrm{p}}\left(\mathbf{x}_{\mathrm{m}}, \mathbf{x}_{\mathrm{p}}\right)
\end{aligned}
$$

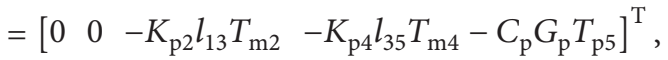

where $G_{\mathrm{p}}$ is the primary helium flowrate, $C_{\mathrm{p}}$ is the helium specific heat, $T_{\mathrm{p} i}$ is the helium temperature at point $i(i=$ $1, \ldots, 5), K_{\mathrm{p} 2}$ and $K_{\mathrm{p} 4}$ are the heat transfer coefficients between the primary side and tube wall of the subcooled and boiling sections, respectively, and $K_{\mathrm{s} 2}$ and $K_{\mathrm{s} 4}$ are, respectively, the heat transfer coefficients between the tube wall and secondary side of the subcooled and boiling sections.

2.3. Secondary-Loop FFN. After the hot helium leaves the reactor, it flows into the OTSG primary side where it transfers the heat to the secondary feedwater. By absorbing the heat of the primary loop, the feedwater is converted to the superheated steam in $571^{\circ} \mathrm{C}$ and about $13.9 \mathrm{MPa}$ or so. The 


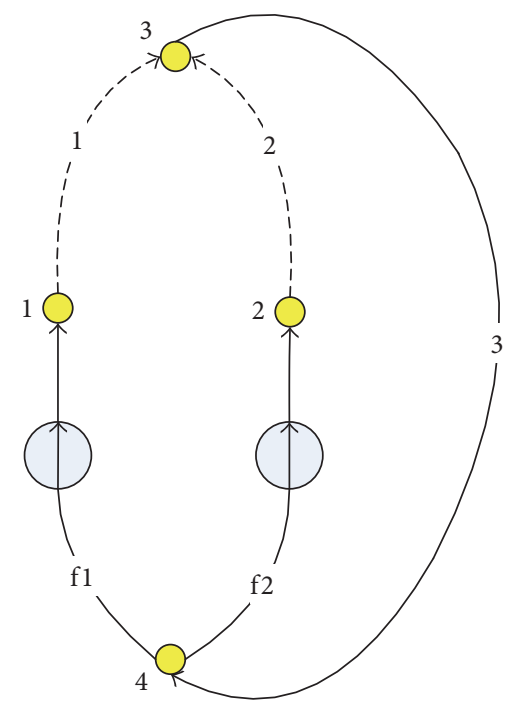

FIGURE 5: Fluid flow network of the secondary loop of the HTR-PM plant.

main steam flow at 13.24 MPa combined from the two NSSS modules then enters the steam turbine for producing electricity. The condensed flow is fed into the OTSG secondary side again after it goes through the grand heater, low pressure heaters (LPHs), deaerator, and high pressure heaters (HPHs). Thus, the hydraulics of the secondary-loop system can be modeled as the FFN shown in Figure 5, where branches $f_{1}$ and $f_{2}$ are the fan branches of which everyone has a feedwater pump, branches 1 and 2 denote the secondary side of the OTSGs corresponding to the first and second NSSS module respectively, and branch 3 contains the equipment of the plant secondary loop such as the steam turbine, condenser, low pressure heaters, and deaerator.

The flowrate dynamics of branches 1,2 , and 3 can be given as $[28,29]$

$$
\frac{\mathrm{d} \mathbf{Q}}{\mathrm{d} t}+\mathbf{K Q}_{\mathrm{D}}^{2} \mathbf{R}=\mathbf{K H},
$$

where $\mathbf{Q}=\left[Q_{1}, Q_{2}, Q_{3}\right]^{\mathrm{T}}, \mathbf{Q}_{\mathrm{D}}^{2}=[\operatorname{diag}(\mathbf{Q})]^{2}, \mathbf{K}=\operatorname{diag}\left(K_{1}\right.$, $\left.K_{2}, K_{3}\right), \mathbf{R}=\left[R_{1}, R_{2}, R_{3}\right]^{\mathrm{T}}, \mathbf{H}=\left[H_{1}, H_{2}, H_{3}\right]^{\mathrm{T}}$, and $Q_{j}$, $R_{j}, H_{j}$, and $K_{j}$ are the flowrate, resistance, pressure drop, and inertia coefficient of branch $j(j=1,2,3)$, respectively.

Every FFN can be divided into a tree containing the fan branches and its complement, that is, the cotree whose branches are referred to as the links. From Figure 5, the branches with solid line, that is, branches $3, \mathrm{f} 1$, and $\mathrm{f} 2$, constitute the tree of this FFN, and the branches with dashed line, that is, branches 1 and 2, are the links which constitute the cotree. Based on the network property, the pressure drops and the flowrates of the tree branches are not independent and obey the following algebraic equations given by Kirchhoff's voltage law (KVL) and Kirchhoff's current law (KCL) [28]:

$$
\begin{aligned}
{\left[\begin{array}{ll}
H_{1} & H_{2}
\end{array}\right]^{\mathrm{T}} } & =-\left[\begin{array}{ll}
H_{3}+H_{\mathrm{f} 1} & H_{3}+H_{\mathrm{f} 2}
\end{array}\right]^{\mathrm{T}}, \\
{\left[\begin{array}{lll}
Q_{3} & Q_{\mathrm{f} 1} & Q_{\mathrm{f} 2}
\end{array}\right]^{\mathrm{T}} } & =\left[\begin{array}{lll}
Q_{1}+Q_{2} & Q_{1} & Q_{2}
\end{array}\right]^{\mathrm{T}},
\end{aligned}
$$

where $H_{\mathrm{f} j}$ is the pressure drop of fan branch $j(j=1,2)$ and can be further expressed as

$$
H_{\mathrm{f} j}=-H_{\mathrm{d} j}+R_{\mathrm{f} j} Q_{\mathrm{f} j}, \quad j=1,2 .
$$

Then, based on (18) and (19), the hydraulics of the FFN shown in Figure 4 can be given by differential-algebraic system [29]:

$$
\begin{aligned}
& \frac{\mathrm{d} \mathbf{Q}_{\mathrm{c}}}{\mathrm{d} t}=-\mathbf{K}_{\mathrm{c}}\left(\mathbf{R}_{\mathrm{f}} \mathbf{Q}_{\mathrm{c}}+\mathbf{Q}_{\mathrm{cD}}^{2} \mathbf{R}_{\mathrm{c}}\right)+\mathbf{K}_{\mathrm{c}}\left(\mathbf{H}_{\mathrm{d}}-H_{3} \boldsymbol{\eta}\right), \\
& \bar{K} H_{3}=\mathbf{k}_{\mathrm{c}}^{\mathrm{T}} \mathbf{H}_{\mathrm{d}}-\mathbf{k}_{\mathrm{fc}}^{\mathrm{T}} \mathbf{Q}_{\mathrm{c}}-\mathbf{k}_{\mathrm{c}}^{\mathrm{T}} \mathbf{Q}_{\mathrm{cD}}^{2} \mathbf{R}_{\mathrm{c}}+K_{3} Q_{3}^{2} R_{3},
\end{aligned}
$$

where $\mathbf{Q}_{\mathrm{c}}=\left[Q_{1}, Q_{2}\right]^{\mathrm{T}}, \mathbf{Q}_{\mathrm{cD}}^{2}=\left[\operatorname{diag}\left(Q_{1}, Q_{2}\right)\right]^{2}, \mathbf{k}_{\mathrm{c}}=\left[K_{1}\right.$, $\left.K_{2}\right]^{\mathrm{T}}, \mathbf{k}_{\mathrm{fc}}=\left[K_{1} R_{\mathrm{f} 1}, K_{2} R_{\mathrm{f} 2}\right]^{\mathrm{T}}, \bar{K}=K_{1}+K_{2}+K_{3}, \mathbf{K}_{\mathrm{c}}=\operatorname{diag}\left(K_{1}\right.$, $\left.K_{2}\right), \mathbf{R}_{\mathrm{f}}=\operatorname{diag}\left(R_{\mathrm{f} 1}, R_{\mathrm{f} 2}\right)$, and $\boldsymbol{\eta}=\left[\begin{array}{ll}1 & 1\end{array}\right]^{\mathrm{T}}$.

2.4. Model Integration. The above dynamic models of the MHTGR, OTSG, and secondary-loop FFN can be integrated together with other commonly utilized models such as the turbine and the synchronous generator to form the dynamic model for the whole plant. Based upon this model, a simulation code for the dynamic behavior and control characteristics of the HTR-PM plant is developed under MATLAB/ Simulink platform, and the composition of this Simulink model is shown in Figure 6. This model can incorporate the plant control laws proposed in the next section for giving the simulations of the operational and control characteristics of the HTR-PM plant, where the program modules named as " $1 \#$ NSSS" and " $2 \#$ NSSS" are used to simulate the dynamic behavior of the two NSSS modules, the program module named as "secondary-loop FFN" is used to simulate the thermal hydraulics for the secondary-loop FFN, the module "Secondary Thermal Feature" is used to simulate the thermodynamics of secondary-loop systems, and module "Generator" is used to simulate the electric generator dynamics. Furthermore, some important model parameters are given in Table 1.

\section{Plant Power Control}

Plant control is a key technique to provide safe, stable, and efficient operation for every nuclear plant and to balance the power supply and demand. Since the two NSSS modules of the HTR-PM plant are coupled together by the common secondary loop including the turbine/generator set, and since the side-by-side arranged MHTGR and OTSG of a NSSS module are tightly coupled with each other through the connecting pipes, it is more difficult to design a power control strategy for the two-modular HTR-PM plant than for those traditional single-modular traditional nuclear plants. Furthermore, the HTR-PM plant is essentially a largescale and multi-input-multioutput (MIMO) nonlinear system whose complexity in its dynamics certainly leads to the complexity in its plant control strategy, while, in the practical engineering, a single control loop is usually utilized to regulate a single process parameter such as the nuclear power, primary flow, feedwater flow, helium temperature, and steam 


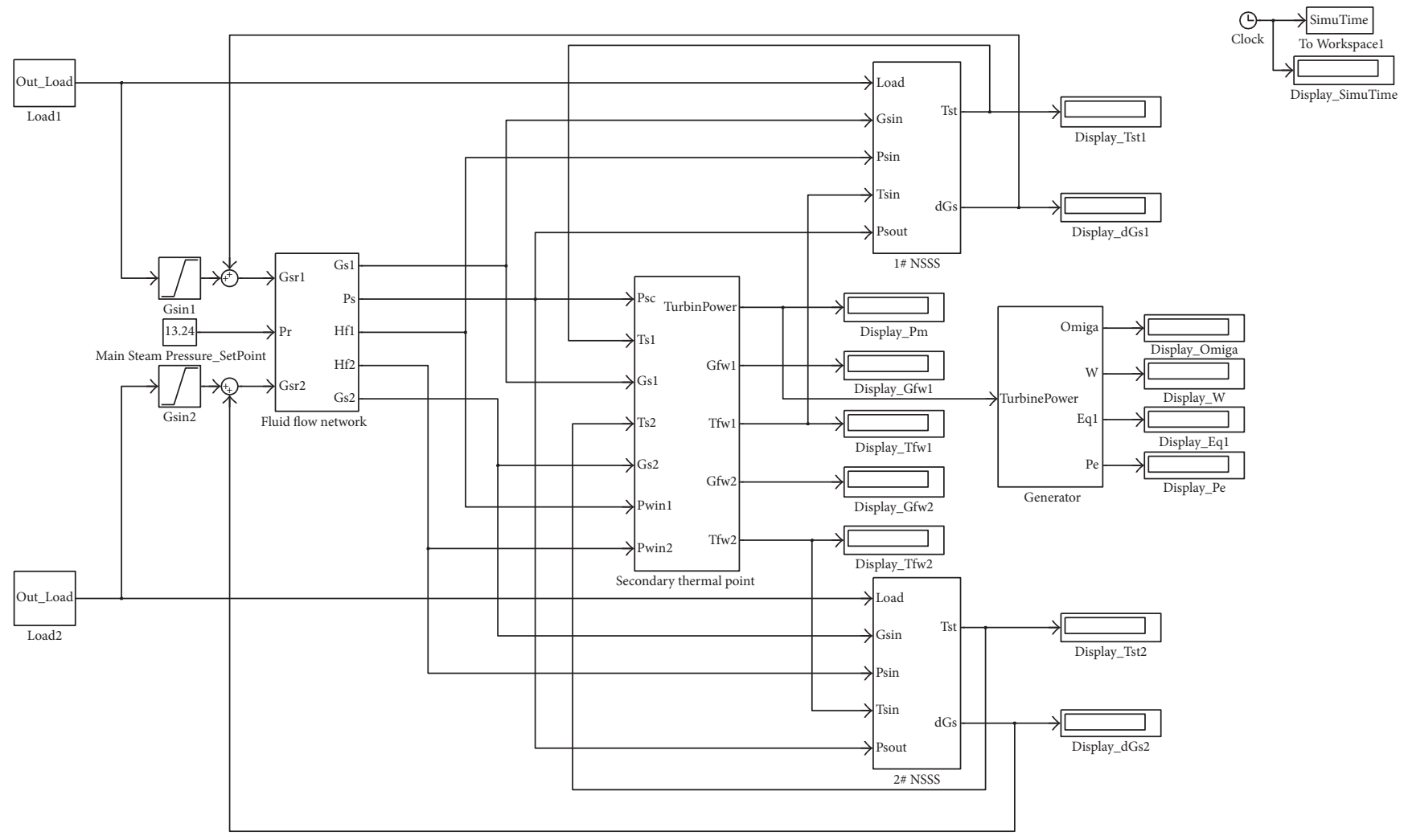

FIgURE 6: Composition of the SIMULINK code.

temperature. Since the combination of all these single control loops deeply affects the plant dynamic behavior, it is necessary to coordinate these control loops for satisfactory closedloop stability as well as transient performance. In this section, the control design method is first reviewed, and the control realization including feedback loops and control laws is then given.

3.1. Control Design Method. The control design mainly lies in two aspects, that is, feedback loop design and control law design, which are tightly related to each other. There have been many process control system design approaches such as the relative gain analysis- (RGA-) based method. In this paper, both the feedback loops and control laws of HTRPM control system are designed by the use of the physicsbased NSSS control method proposed in [30-36] and module coordination control method proposed in [28, 29], which provide the globally asymptotic closed-loop stability through guaranteeing the convergence of Lyapunov functions determined by the shifted-ectropies of neutron kinetics and thermodynamics as well as the kinetic energy stored in secondary-loop FFN.

3.1.1. NSSS Module Control. Both the MHTGR and OTSG are complex nonlinear dynamic systems, and their dynamics are tightly coupled with each other due to their side-byside arrangement. To improve both the steady and transient performance, it is necessary to give proper control laws for the NSSS module composed of the MHTGR and OTSG by considering the nonlinear dynamics. The physics-based control (PBC) method is an effective way to design nonlinear reactor control laws by retaining or strengthening stable subdynamics and by cancelling or suppressing unstable subdynamics, which has been applied to the load-following control design for the PWR [30, 31], MHTGR [32-34], and OTSG [35]. Very recently, based upon the $\mathrm{PBC}$ method, a novel model-free MHTGR-based NSSS module control strategy was proposed in [36], which provides globally asymptotic stability (GAS) for the NSSS module if the feedwater temperature is constant and both the helium and feedwater flowrate are well regulated. This NSSS module control strategy can be realized by feedback loops given in Section 3.2.1 and simple control laws given in Section 3.3.1.

3.1.2. Coordination Control of Multiple NSSS Modules. Through the multimodular scheme, the inherent safety of the MHTGR is applicable to the large-scale plants with any desired power ratings. Module coordination control is one of the most important characteristics of the multimodular nuclear plants such as the HTR-PM with comparison to the control of those traditional single module nuclear plants. It has been revealed in [29] that the module coordination problem is essentially a flowrate-pressure regulation problem of the secondary-loop FFN. Moreover, based on the dissipation 
TABLE 1: Main parameters of the dynamic model.

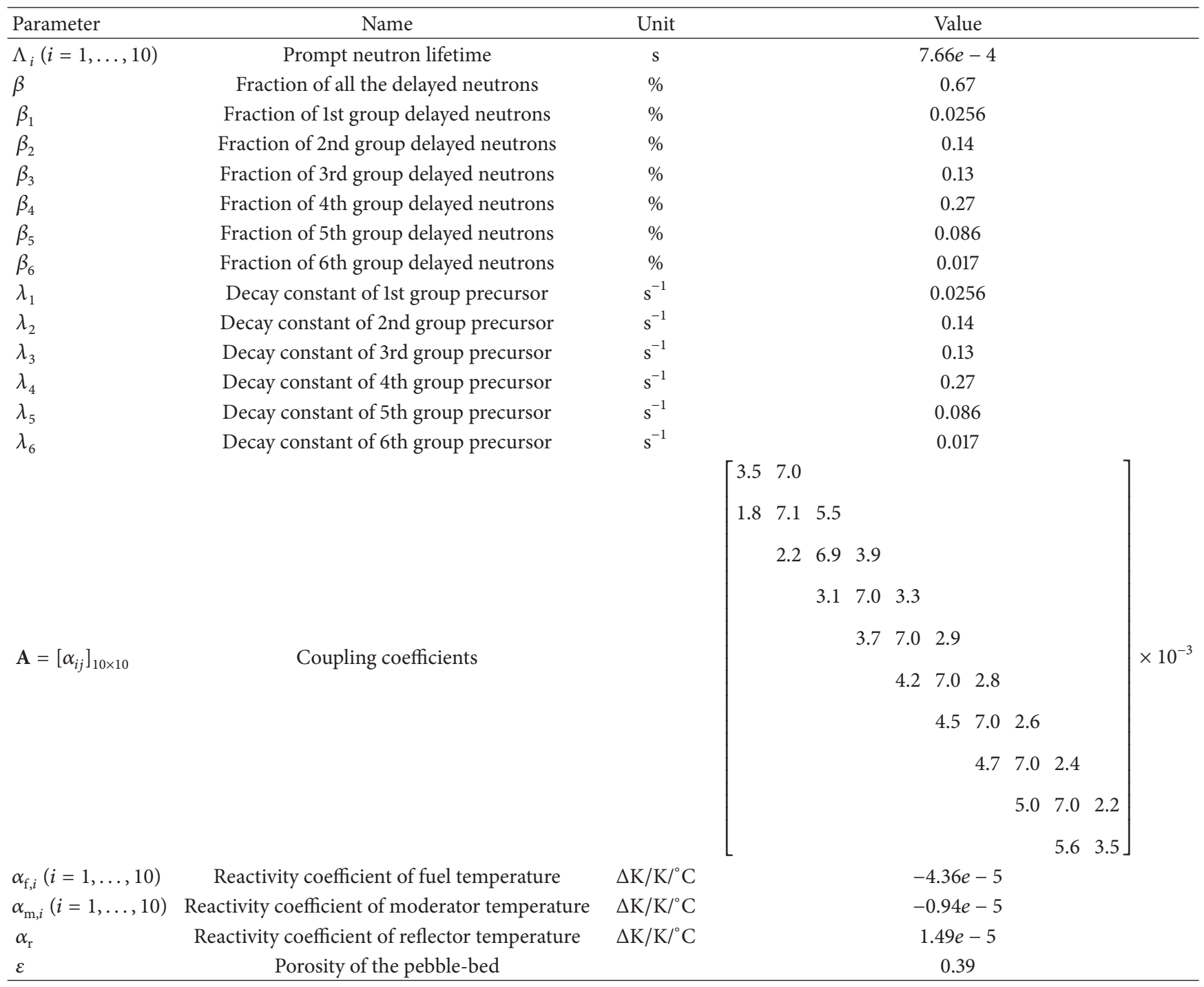

structure of the FFNs, it has also been proved in [29] that feedback loops given in Section 3.2.2 and control laws given in Section 3.3.2 can provide globally input-to-state stability (ISS) and satisfactory transient performance for the cotree flowrates and tree branch pressure drops for the secondaryloop FFN.

3.2. Feedback Loops and Controller Functions. All the feedback loops of the plant control system of the HTR-PM plant are shown in Figure 7. Since the feedback loops of the two NSSS modules are the same with each other, only those of the first NSSS module are illustrated. From Figure 2, we can see that the plant control system is constituted by the controllers for regulating the reactor nuclear power, primary helium flowrate, secondary feedwater flowrate, outlet helium temperature, steam temperature, reactor thermal power, and main steam pressure as well as the controller for discharge and bypass. Based on their functions, these controllers can be classified to the layers of module control, module coordination, and supervisory as well as bypass and discharge.

3.2.1. Module Control. The layer of module control is composed of the controllers for regulating the nuclear power, helium flowrate, reactor outlet helium temperature, steam temperature, and NSSS output thermal power. The functions of these five controllers are given as follows.

(1) Nuclear Power Controller. It regulates the neutron flux by generating both the given direction and velocity signals that determine the control rod movement. These signals are utilized to drive the stepping motors belonging to the reactor control rod mechanism for realizing the given movement. The movement of the control rods induces satisfactory reactivity to the reactor, which guarantees the 


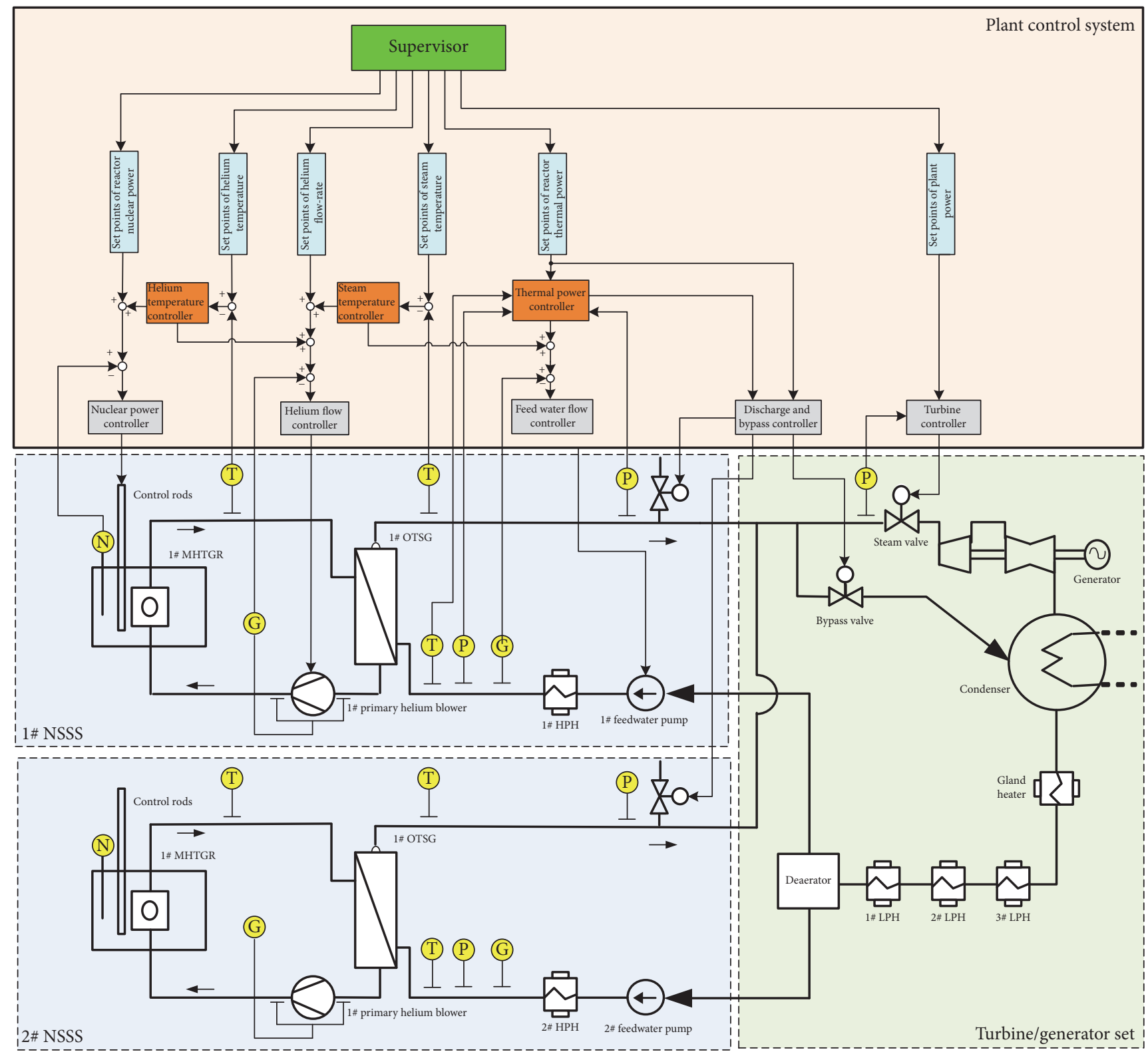

FIgURE 7: Composition of HTR-PM plant control system.

stability and transient performance of the reactor neutron flux.

(2) Helium Flow Controller. Satisfactory primary helium circulation is the precondition of transferring the heat produced by the fission reaction to the secondary loop for steam generation. In order to provide enough pressure header for the primary helium circulation, the helium flow controller gives the referenced frequency for the variable frequency driver (VFD) of the induction motor that drives the primary helium blower.

(3) Feedwater Flow Controller. It regulates the secondary feedwater flowrates of the OTSGs through adjusting the rotational speed of the feedwater pumps by their hydraulic couplings. It is worth noting that the feedwater flowrate controller is responsible for the stability and transient performance of not only the NSSS modules but also the secondary-loop FFN of the HTR-PM plant.

(4) Helium Temperature Controller. It regulates the reactor outlet helium temperature by properly adjusting the setpoints of the nuclear power controller and (or) helium flow controller. Specifically, if there is only modification of the referenced relative nuclear power, then the helium temperature controller and the nuclear power controller constitute a cascaded feedback loop, where the former one is in the outer loop as the major controller, and the latter one is in the inner loop as minor controller.

(5) Steam Temperature Controller. It regulates the outlet steam temperature of the OTSG by properly adjusting the 
setpoints of the helium flowrate controller and (or) feedwater flowrate controller. Specifically, if its output is only the revision of the setpoints of the primary helium flowrate, then the steam temperature controller serves as the major regulator of the cascaded loop formed with the helium flow controller. Moreover, if its output is only the revision for the referenced feedwater flowrate, then the steam temperature controller and feedwater flow controller form a cascaded loop where the former one is the major regulator. In the power operation stage of the HTR-PM plant, the OTSG outlet steam temperature should be kept to be $571^{\circ} \mathrm{C}$ constantly.

(6) Thermal Power Controller. It is essentially a feedforward controller that gives the referenced feedwater flowrate based on both the setpoint of NSSS thermal power and the measurement of the temperatures and pressures of the feedwater and outlet superheated steam of each OTSG.

3.2.2. Module Coordination. The two NSSS modules of the HTR-PM plant are tightly coupled with each other through the common secondary-loop FFN. To regulate the feedwater flowrate of 1 \# NSSS module, it is necessary to adjust $H_{\mathrm{d} 1}$ by revising the rotating speed of the pump. However, from model (21), the variation of $H_{\mathrm{d} 1}$ influences not only the feedwater flowrate of 1 \# NSSS module but also pressure drop $\mathrm{H}_{3}$ which can be utilized to measure the main steam pressure. Then, from (21), the variation in $\mathrm{H}_{3}$ influences the dynamic behavior of the feedwater flowrate of 2\# NSSS module, which induces the need of adjusting $H_{\mathrm{d} 2}$ for keeping this feedwater flowrate. Therefore, regulating the feedwater flowrate of one NSSS module needs to adjust the rotating speeds of the two pumps, and each NSSS feedwater flowrate can influence the main steam pressure. The module coordination is just the flowrate-pressure control of the secondary-loop FFN.

It has been proved theoretically in [29] that the FFN flowrate regulation can be realized by distributed controllers of which each one only needs the measurement of the flowrate to be regulated. Thus, the NSSS feedwater flowrate controllers can well guarantee the stability and transient performance of the flowrates of the HTR-PM secondary-loop FFN shown in Figure 7. Moreover, in the power operation stage of the HTR-PM plant, the main steam pressure should be kept to be 13.24 MPa constantly. The stability of the main steam pressure is a basic operation requirement of the OTSG and also indicates the power balance between NSSS modules and the turbine/generator. Here, the main steam pressure of the HTRPM plant is regulated by the turbine controller which provides the main steam pressure stability through adjusting the opening of the main steam valve. Thus, the collaboration of the NSSS feedwater flowrate controllers and the turbine controller realizes the flowrate-pressure regulation of the secondary-loop FFN, which achieves the function of NSSS module coordination and keeps the power balance between the NSSS modules and turbine.

3.2.3. Supervisor. The supervisor gives the setpoint of the thermal power for every NSSS module according to the requirement of the power grid and has no feedback regulation function. Moreover, it also contains the map from the referenced NSSS thermal power to the referenced values of the NSSS process variables including the reactor nuclear power, primary helium flowrate, secondary feedwater flowrate, reactor outlet helium temperature, OTSG outlet steam temperature, and main steam pressure, which gives the setpoints of all the controllers. The supervisor can be viewed as an input-output (IO) interface between the power plant and the power grid so as to improve the power balance quality between the grid and plant.

3.2.4. Bypass and Discharge. The function bypass and discharge guarantee the operationability of the HTR-PM plant in some tough cases. The bypass controller opens the bypass valve so that the OTSG outlet steam flows into the condenser in the cases of load rejection, reactor startup, turbine bypass, and so forth. The function of the bypass controller is essentially providing a virtual load to compensate the large difference between the thermal inertias of the NSSS and turbine. The discharge controller opens the discharge valve if the pressure of the outlet steam is larger than its maximal value and closes the valve when the steam pressure is lower than a given value.

3.3. Control Laws. The control laws for the nuclear power, primary helium flowrate, feedwater flowrate, MHTGR outlet helium temperature, OTSG outlet steam temperature, and main steam pressure, which have the feedback regulation function, are all given in this subsection. These control laws can be classified into control laws for NSSS modules and those for module coordination.

3.3.1. Module Control Laws. The module control laws include the feedback regulation algorithms of the nuclear power, primary helium flowrate, feedwater flowrate, MHTGR outlet helium temperature, and OTSG outlet steam temperature, which are designed based on the physics-based NSSS control method proposed in [30-36].

(1) Nuclear Power Control Law. The nuclear power control laws is designed to be proportional-differential (PD) feedback regulation algorithm with the transfer function given by

$$
G_{\mathrm{N}}(s)=\frac{u_{\mathrm{N}}(s)}{\mathrm{n}_{\mathrm{r}, \mathrm{e}}(s)}=k_{\mathrm{n}, \mathrm{p}}+\frac{k_{\mathrm{n}, \mathrm{d}} s}{\tau_{\mathrm{n}, \mathrm{d}} s+1},
$$

where positive scalars $k_{\mathrm{n}, \mathrm{p}}$ and $\tau_{\mathrm{n}, \mathrm{d}}$ are, respectively, the proportional and differential feedback gains, $\tau_{\mathrm{n}, \mathrm{d}}$ is a small inertia time constant, $u_{\mathrm{N}}$ is the setpoint of the control rod speed signal used to drive stepping motors of the control rod driving mechanism, and $n_{\mathrm{r}, \mathrm{e}}$ is the mismatch of the referenced relative nuclear power $n_{\mathrm{r}, \mathrm{r}}$ from its actual value $n_{\mathrm{r}}$; that is, $n_{\mathrm{r}, \mathrm{e}}=$ $n_{\mathrm{r}, \mathrm{r}}-n_{\mathrm{r}}$. It is necessary to note that relative nuclear power is the normalized reactor neutron concentration, and the total thermal power is the outlet thermal power of the NSSS module. The steady values of the relative nuclear power is calibrated by that of total thermal power through experiment. 
(2) Helium Flow Control Law. The feedback control of the primary helium flowrate adopts the proportional-integral (PI) law with its transfer function given by

$$
G_{\mathrm{HF}}(s)=\frac{u_{\mathrm{HF}}(s)}{W_{\mathrm{H}, \mathrm{e}}(s)}=k_{\mathrm{hf}, \mathrm{p}}+\frac{k_{\mathrm{hf}, \mathrm{i}}}{s},
$$

where positive constants $k_{\mathrm{hf}, \mathrm{p}}$ and $k_{\mathrm{hf}, \mathrm{i}}$ are, respectively, the proportional and integral feedback gains, $u_{\mathrm{HF}}$ is the referenced rotating speed of the primary helium blower, and $W_{\mathrm{H}, \mathrm{e}}$ is the error between the referenced and actual values of the primary helium flowrate.

(3) Feedwater Flow Control Law. The NSSS module feedwater flowrate is also regulated by PI control law, which is given by

$$
G_{\mathrm{FW}}(s)=\frac{u_{\mathrm{FW}}(s)}{W_{\mathrm{fw}, \mathrm{e}}(s)}=k_{\mathrm{fw}, \mathrm{p}}+\frac{k_{\mathrm{fw}, \mathrm{i}}}{s},
$$

where positive scalars $k_{\mathrm{fw}, \mathrm{p}}$ and $k_{\mathrm{fw}, \mathrm{i}}$ are, respectively, the corresponding proportional and integral gains, $u_{\mathrm{FW}}$ is the driving signal of the hydraulic coupling, and $W_{\mathrm{fw}, \mathrm{e}}$ is the error between the referenced and actual values of the feedwater flowrate.

(4) MHTGR Outlet Helium Temperature Control Law. The reactor outlet helium temperature is regulated by the lead-lag feedback law that is given by transfer functions:

$$
\begin{aligned}
& G_{\mathrm{HT} 1}(s)=\frac{u_{\mathrm{HT} 1}(s)}{T_{\mathrm{HO}, \mathrm{e}}(s)}=\frac{k_{\mathrm{ht} 1, \mathrm{p}}+k_{\mathrm{ht}, \mathrm{d}} s}{k_{\mathrm{n}, \mathrm{p}}+k_{\mathrm{n}, \mathrm{d}} s}, \\
& G_{\mathrm{HT} 2}(s)=\frac{u_{\mathrm{HT} 2}(s)}{T_{\mathrm{HO}, \mathrm{e}}(s)}=-\left(k_{\mathrm{ht} 2, \mathrm{p}}+\frac{k_{\mathrm{ht}, \mathrm{i}}}{s}\right),
\end{aligned}
$$

where $k_{\mathrm{n}, \mathrm{p}}$ and $k_{\mathrm{n}, \mathrm{d}}$ are, respectively, the proportional and differential gains of the nuclear power control law, gains $k_{\mathrm{ht} j \mathrm{p}}$ $(j=1,2), k_{\mathrm{ht}, \mathrm{d}}$, and $k_{\mathrm{ht}, \mathrm{i}}$ are positive constants determining the lead-lag performance, $u_{\mathrm{HT} 1}$ is the revision to the setpoint of the relative nuclear power, $u_{\mathrm{HT} 2}$ is the revision to the referenced primary helium flowrate, $T_{\mathrm{HO}, \mathrm{e}}$ is the error between the setpoint and measurement of the reactor outlet helium temperature.

(5) OTSG Outlet Steam Temperature Control Law. The OTSG outlet steam temperature of every NSSS module is regulated by PI feedback laws:

$$
\begin{aligned}
& G_{\mathrm{S} 1}(s)=\frac{u_{\mathrm{S} 1}(s)}{T_{\mathrm{S}, \mathrm{e}}(s)}=k_{\mathrm{s} 1, \mathrm{p}}+\frac{k_{\mathrm{s} 1, \mathrm{i}}}{s}, \\
& G_{\mathrm{S} 2}(s)=\frac{u_{\mathrm{S} 2}(s)}{T_{\mathrm{S}, \mathrm{e}}(s)}=-\left(k_{\mathrm{s} 2, \mathrm{p}}+\frac{k_{\mathrm{s} 2, \mathrm{i}}}{s}\right),
\end{aligned}
$$

where positive constants $k_{\mathrm{s} j, \mathrm{p}}$ and $k_{\mathrm{s} j \mathrm{i}}(j=1,2)$ are, respectively, the proportional and integral feedback gains, $u_{\mathrm{S} 1}$ is the revision of the setpoint of the primary helium flowrate, $u_{\mathrm{S} 2}$ is the revision of the setpoint of the secondary feedwater flowrate, and $T_{\mathrm{s}, \mathrm{e}}$ is the error between the setpoint and measurement of the OTSG outlet steam temperature.
3.3.2. Module Coordination Laws. The NSSS module coordination laws are just the flowrate-pressure feedback control laws for the secondary-loop FFN flowrates and pressure drop, which are designed based on the module coordination control method proposed in [28, 29].

(1) FFN Flowrate Control Law. As discussed in Section 3.1.2 and $[28,29]$, the flowrates of a FFN can be well regulated by controlling the flowrates of its cotree branches in a distributed way. From the structure of HTR-PM secondary-loop FFN shown in Figure 5, the OTSG secondary sides of the first and the second NSSS modules form branches 1 and 2 of this FFN which are just the cotree branches. Thus, from the graph properties of the FFN, all the branch flowrates can be well controlled or stabilized by regulating the feedwater flowrates of the OTSGs. Then, it is clear that OTSG feedwater flowrate control law (24) can realize the FFN flowrate control function, which means that flowrate control law (24) belongs to both the layers of module control and module coordination.

(2) FFN Pressure Drop Control Law. The pressure drop of the FFN tree branches (excluding the branches with pump) is also a crucial issue to guarantee the stability and operationability. The pressure drop $\mathrm{H}_{3}$ of the HTR-PM secondary-loop FFN shown in Figure 5 can be measured by the main steam pressure which is regulated by the turbine control law with transfer function given by

$$
G_{\mathrm{SP}}(s)=\frac{u_{\mathrm{SP}}(s)}{P_{\mathrm{S}}(s)}=k_{\mathrm{p}, \mathrm{p}}+\frac{k_{\mathrm{p}, \mathrm{i}}}{s} .
$$

Here, in (27), positive scalars $k_{\mathrm{p}, \mathrm{p}}$ and $k_{\mathrm{p}, \mathrm{i}}$ are, respectively, the proportional and integral gains, $u_{\mathrm{SP}}$ is the setpoint of the steam valve opening, and $P_{\mathrm{S}, \mathrm{e}}$ is the mismatch of the referenced main steam pressure from its actual value.

3.3.3. Parameters of Control Laws. The plant control performance relies on the two aspects, that is, the performances of both the module control and module coordination. The former one is guaranteed by the physics-based NSSS control approach, and the latter one is provided by the FFN flowratepressure control method. All the control laws take the form as PI or PD feedback laws. For PI control laws, the proportional gain is larger, and the response is faster, but if it is too large, the control action will hit the saturation margin, which leads to the deterioration of closed-loop stability. Moreover, the integral gain is larger, and the transition period to the steady state is shorter, but the overshoot is larger. Usually, proportional gain is chosen not larger than 1.0, and the integral gain is chosen not larger than 0.1. For the PD law for nuclear power regulation, the proportional gain is chosen not larger than 0.5 , and the differential gain is chosen not larger than 3.0 .

\section{Simulation Results with Discussions}

In this section, the dynamic behavior of the HTR-PM plant in both the cases of power step and ramp are studied through the numerical simulation. This study is performed based on 

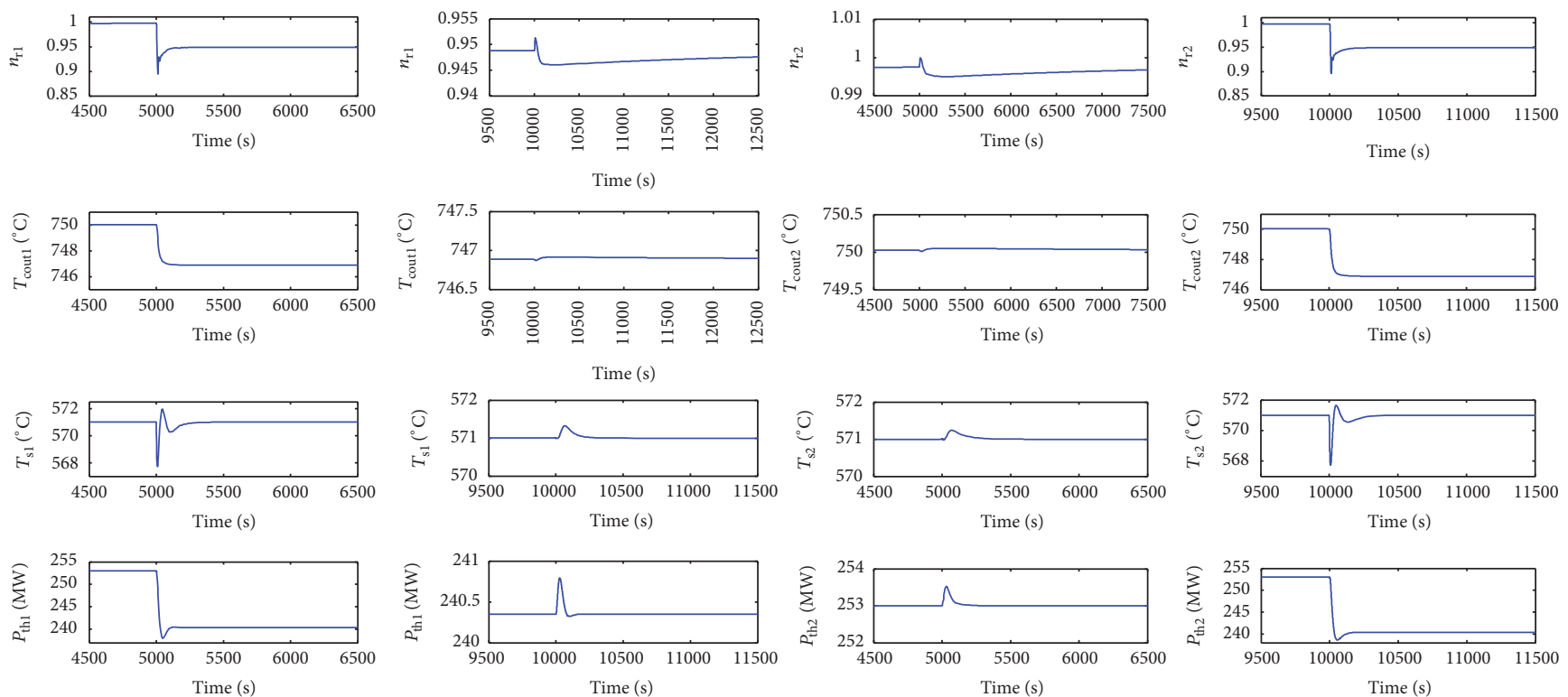

FIGURE 8: Responses of 1\# and 2\# NSSS in the case of power step-down: $n_{\mathrm{ri}}, T_{\text {couti }}, T_{\mathrm{si}}$, and $P_{\mathrm{thi}}$ are, respectively, the relative nuclear power, MHTGR outlet helium temperature, OTSG outlet steam temperature, and total thermal power of the $i$ th NSSS, $i=1,2$.

the MATLAB/Simulink simulation code shown in Figure 6 that integrates both the plant model introduced in Section 2 and control strategy given in Section 3. Moreover, necessary discussions are also given in this section.

\subsection{Simulation Results}

4.1.1. Power Step. The dynamic responses of the power step between $100 \%$ and $95 \%$ plant full power (PFP) are obtained through numerical simulation.

(1) Power Step-Down. Initially, the HTR-PM plant remains at the steady state of $100 \%$ PFP which means that the two NSSS modules are running at the $100 \%$ reactor full power (RFP). At 5000 s, the thermal power setpoint of the first (i.e., 1\#) NSSS module steps down from $100 \%$ to $95 \%$ RFP, and then at $10000 \mathrm{~s}$, the referenced thermal power of the second (i.e., 2\#) NSSS module steps down from $100 \%$ to $95 \%$ RFP. The dynamic responses of the relative nuclear powers, reactor outlet helium temperatures, OTSG outlet steam temperatures, and thermal powers of $1 \#$ and 2\# NSSS modules are given in Figure 8 . The responses of flowrates $Q_{i}(i=1,2,3)$, feedwater pressures $-H_{\mathrm{f} k}(k=1,2)$, and main steam pressure $H_{3}$ are illustrated in Figure 9.

(2) Power Step-Up. Initially, the HTR-PM plant remains at the steady state of 95\% PFP; that is, the two NSSS modules operate at 95\% RFP. The thermal power setpoints of $1 \#$ and 2\# NSSS modules step up from $95 \%$ to $100 \%$ RFP at $5000 \mathrm{~s}$ and $10000 \mathrm{~s}$, respectively. The dynamic responses of the relative nuclear powers, reactor outlet helium temperatures, OTSG outlet steam temperatures, and thermal powers of $1 \#$ and 2\# NSSS modules are given in Figure 10. The responses of $Q_{i}$ $(i=1,2,3),-H_{\mathrm{f} k}(k=1,2)$, and $H_{3}$ are shown in Figure 11 .
4.1.2. Power Ramp. The responses of the steady power ramp between $100 \%$ and $50 \%$ plant full power (PFP) are given by the simulation study.

(1) Power Ramp-Down. Initially, the HTR-PM plant remains at the steady state of $100 \%$ PFP; that is, the two NSSS modules operate at 100\% RFP. At 5000 s, 1\# NSSS module maneuvers from $100 \%$ to $50 \%$ RFP steadily in 10 minutes, and then at $10000 \mathrm{~s}$, the referenced thermal power of 2\# NSSS module changes steadily from $100 \%$ to $50 \%$ RFP in 10 minutes, which is just the power decrease process from $100 \%$ to $50 \%$ PFP of the HTR-PM plant. The responses of the relative nuclear powers, reactor outlet helium temperatures, OTSG outlet steam temperatures, and thermal powers of 1 \# and 2\# NSSS modules are given in Figure 12. The responses of flowrates $Q_{i}(i=$ $1,2,3)$, feedwater headers $-H_{\mathrm{f} k}(k=1,2)$, and main steam pressure $H_{3}$ are illustrated in Figure 13.

(2) Power Ramp-Up. Initially, the HTR-PM plant remains at the steady state of $95 \%$ PFP; that is, the two NSSS modules operate at 95\% RFP. At $5000 \mathrm{~s}$ and $10000 \mathrm{~s}, 1$ \# and 2\# NSSS modules, respectively, maneuver steadily from $50 \%$ to $100 \%$ RFP in 10 minutes, which is the process of HTR-PM power increase from $50 \%$ to $100 \%$ PFP. The responses of the relative nuclear powers, reactor outlet helium temperatures, OTSG outlet steam temperatures, and thermal powers of $1 \#$ and 2\# NSSS modules are given in Figure 14. The responses of flowrates $Q_{i}(i=1,2,3),-H_{\mathrm{f} k}(k=1,2)$, and $H_{3}$ are illustrated in Figure 15.

4.2. Discussions. The variation of the plant power is realized by the successive power maneuver of $1 \#$ and 2\# NSSS modules, and at most one NSSS module can be in the state of 

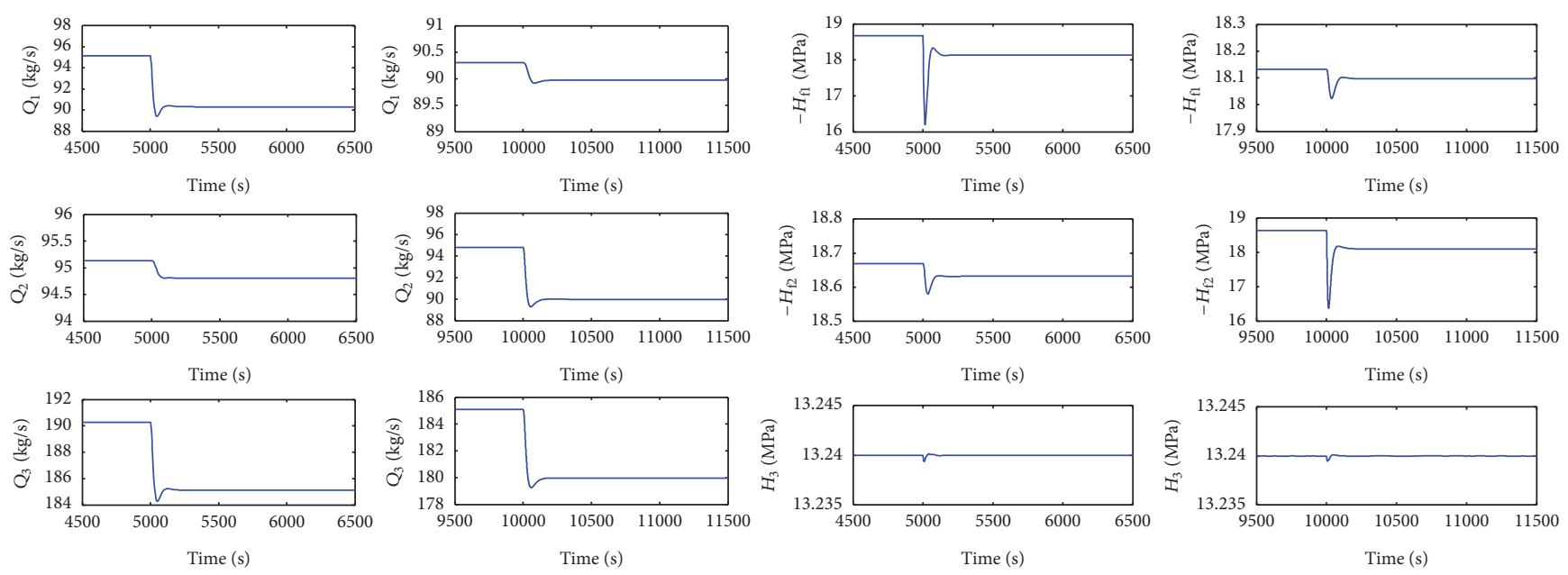

FIGURE 9: Responses of secondary-loop FFN flowrates and pressure drops in the case of power step-down.
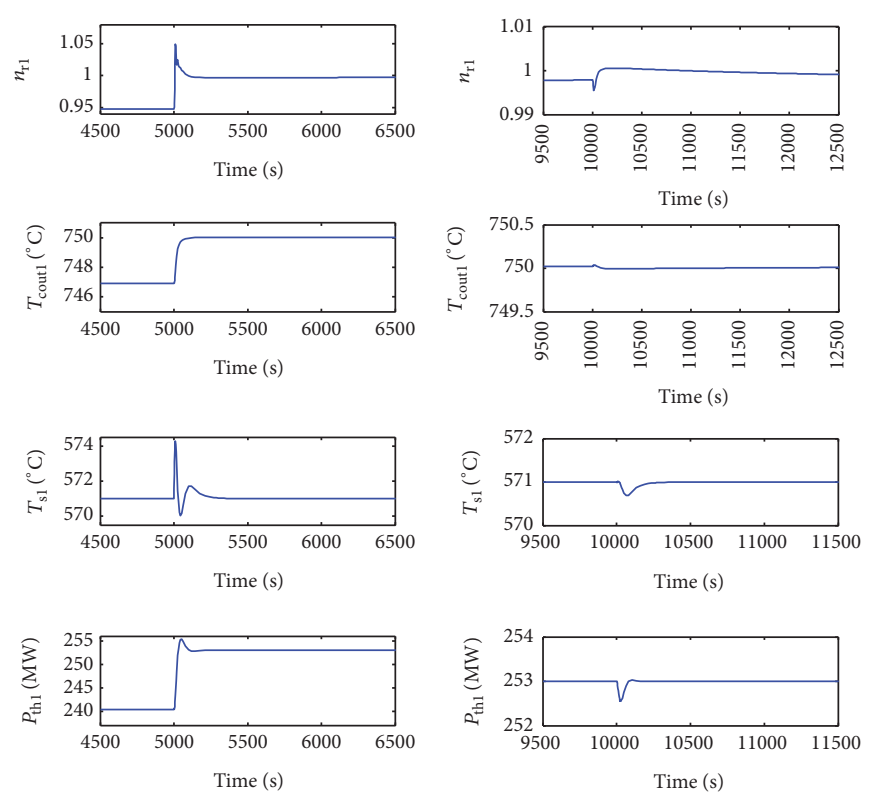
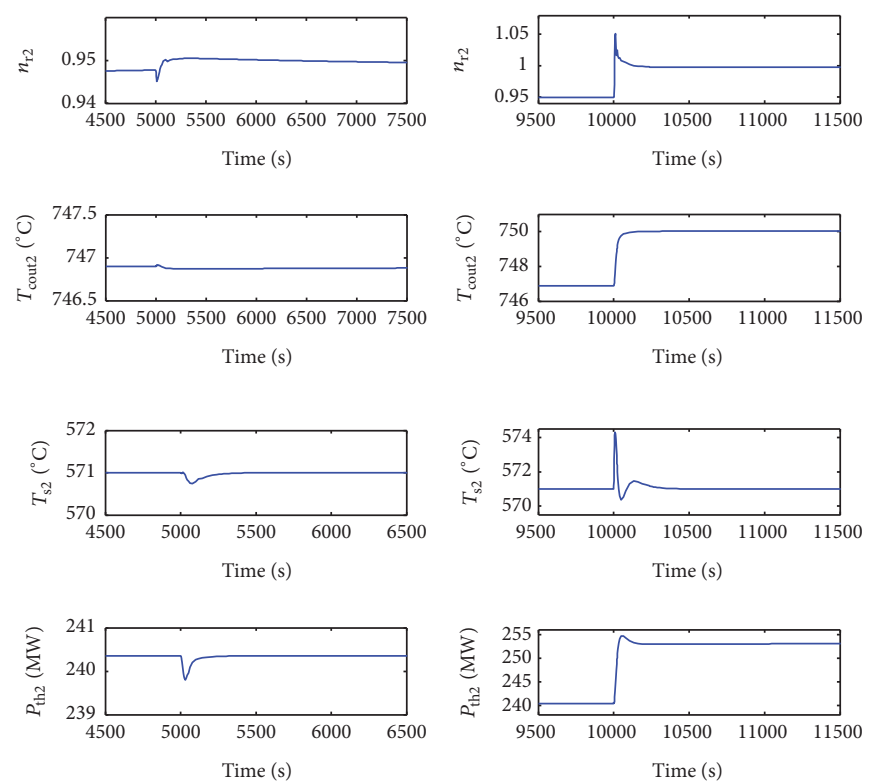

FIGURE 10: Responses of 1\# and 2\# NSSS in the case of power step-up: $n_{\mathrm{ri}}, T_{\text {cout }}, T_{\mathrm{si}}$, and $P_{\mathrm{th} i}$ are, respectively, the relative nuclear power, MHTGR outlet helium temperature, OTSG outlet steam temperature, and total thermal power of the $i$ th NSSS, $i=1,2$.

power maneuver at any time. Generally, from Figures 8-15, the control laws for the modules and those for the module coordination guarantee satisfactory closed-loop stability and transient performance of the process variables of the NSSS modules as well as the secondary-loop FFN.

The variation of a NSSS power-level setpoint directly induces the variations of the setpoints of nuclear power, reactor outlet helium temperature, primary helium flowrate, and secondary feedwater flowrate of this NSSS, which enlarge the errors between the practical values and setpoints of these variables. These errors drive the nuclear power controller and helium temperature controller to insert or withdraw the control rods and drive the flowrate controllers to slow down or speed up the helium blower and feedwater pump. Due to the negative feedback laws, the movement of control rods, helium blower, and feedwater pump can suppress the errors. Moreover, the variations of the flowrates and helium temperature induce the variations of steam temperature and main steam pressure, which drive the steam temperature controller to revise the setpoints of helium or feedwater flowrates for maintaining the steam temperature and drive the pressure controller to change the steam valve opening for keeping the main steam pressure. The variation of the steam valve opening can also reduce the feedwater flowrate of the other NSSS, which leads to the successive variations of steam temperature, helium temperature, fuel temperature, and nuclear power of the other NSSS. Then, the controllers of the other NSSS are active to suppress the errors of process 

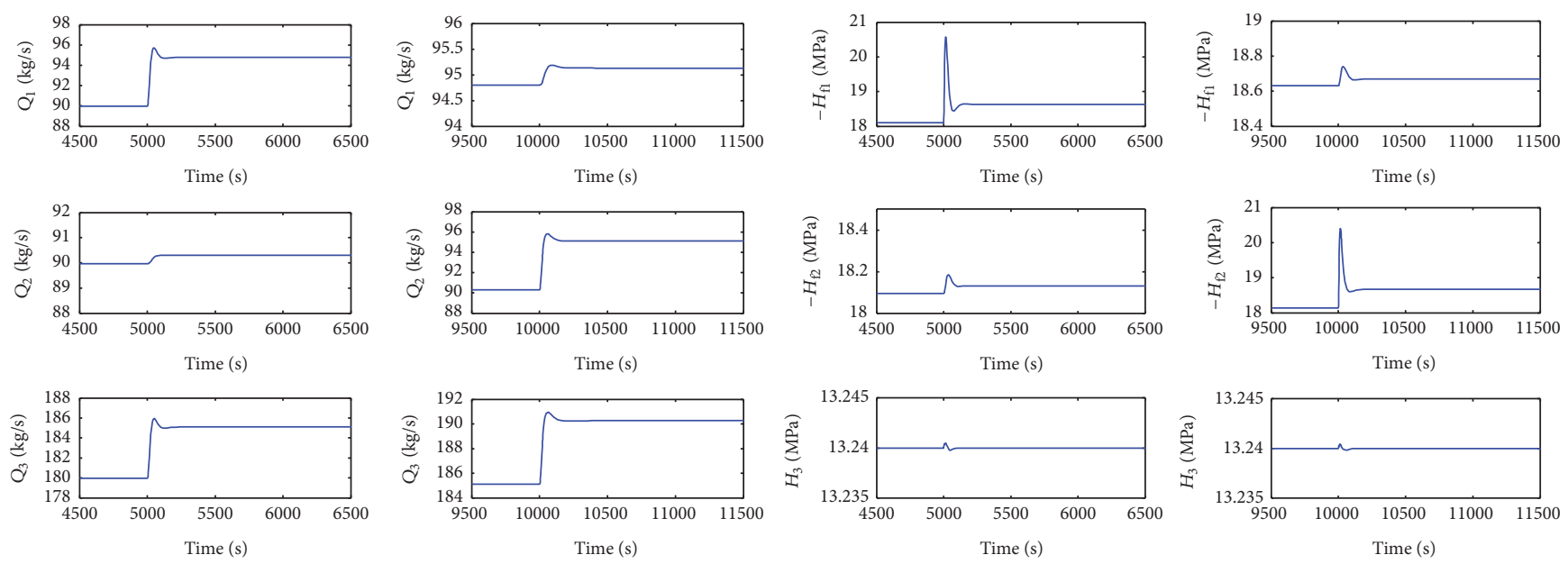

FIGURE 11: Responses of secondary-loop FFN flowrates and pressure drops in the case of power step-up.
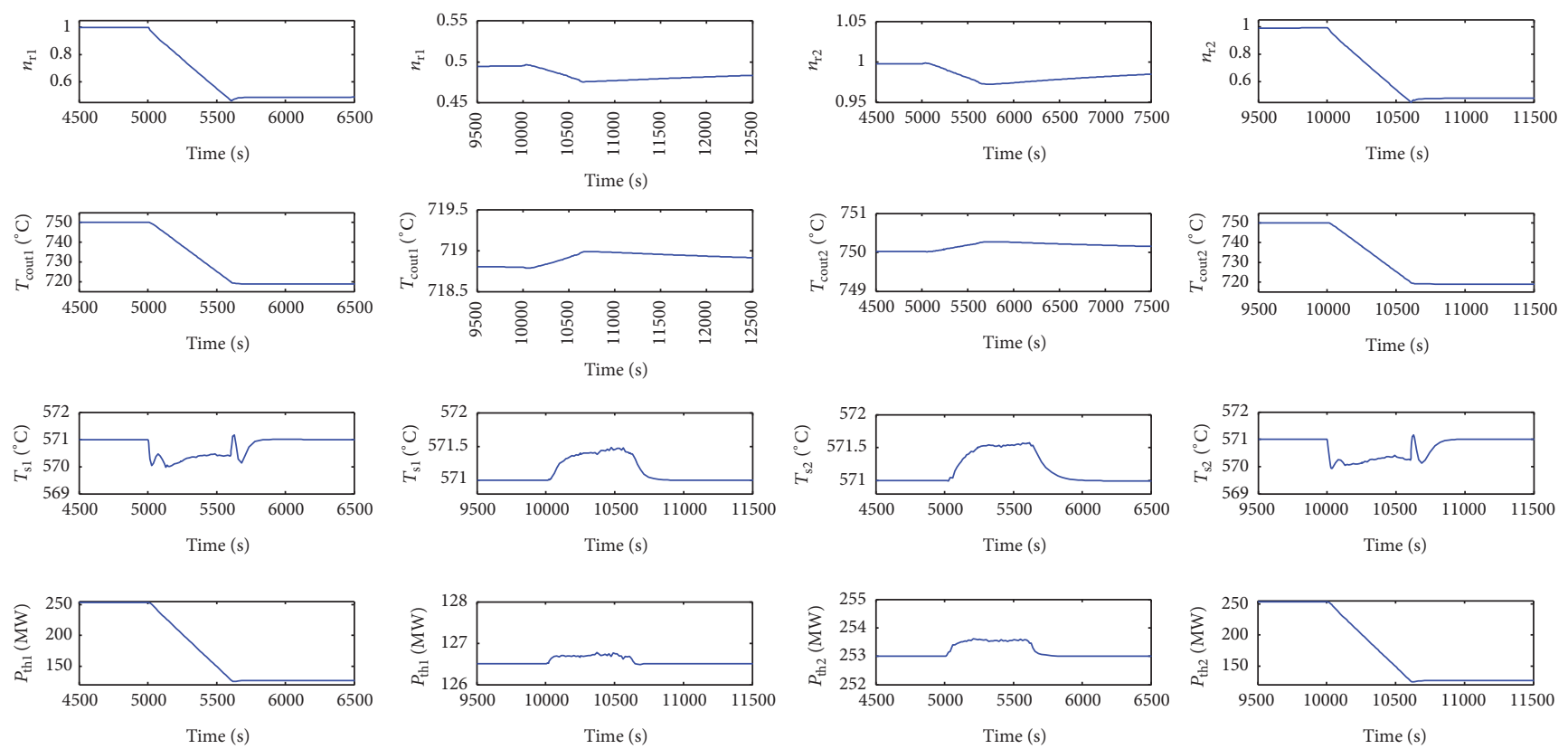

FIGURE 12: Responses of $1 \#$ and 2\# NSSS in the case of power ramp-down: $n_{\mathrm{ri}}, T_{\text {couti }}, T_{\mathrm{si}}$, and $P_{\mathrm{thi}}$ are, respectively, the relative nuclear power, MHTGR outlet helium temperature, OTSG outlet steam temperature, and total thermal power of the $i$ th NSSS, $i=1,2$.

variables caused by the variation of steam valve opening. Furthermore, since the steam flow extracted from the turbine is equally distributed to the two HPHs, the power maneuver of one module changes feedwater temperatures of both two modules. To maintain the thermal powers, the setpoints of feedwater flowrates of the two modules should be adjusted by the thermal power controllers.

Specifically to the NSSS module control performance, we can clearly see from the simulations results illustrated in Figures 8-15 that simple module control laws (22)-(26) can guarantee satisfactory stability and transient performance for the NSSS modules in the cases of power-level maneuver and maintenance. Here, the expressions of these module control laws are given by guaranteeing proper dissipation feature for the NSSS module with its shifted-ectropy as the storage function, which is the key idea of physics-based nuclear plant control method with the ability of giving simple control laws. These simulation results effectively show the feasibility of these module control laws which can be implemented and commissioned easily in the practical engineering.

Furthermore, the key difference between the HTR-PM plant and those single-modular nuclear plants is the module coordination control. There is a tight hydraulic coupling effect of the two NSSS modules that is induced by the common secondary-loop FFN. There is also coupling effect between the feedwater temperatures of the two NSSS modules, which is induced by the equal distribution of the steam flow extracted from the turbine to the two HPHs belonging to the two modules, respectively. Because of the existence of the hydraulic and thermal module coupling effects, when 

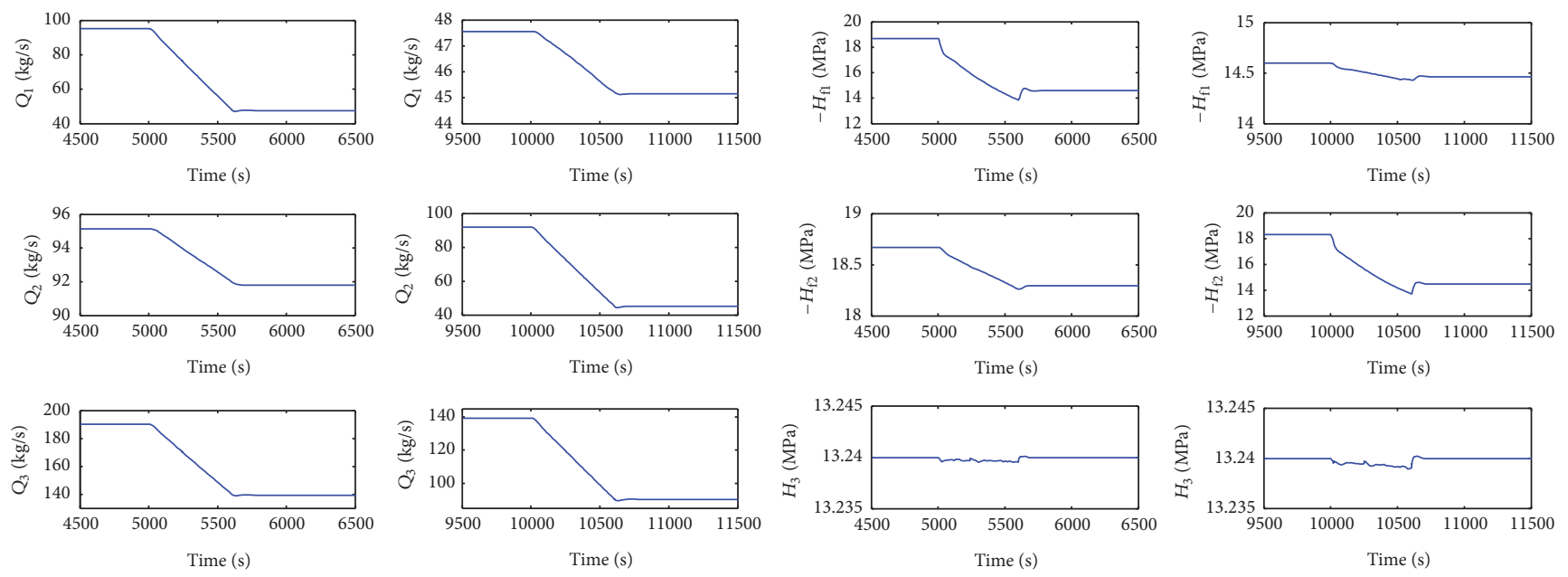

FIGURE 13: Responses of secondary-loop FFN flowrates and pressure drops in the case of power ramp-down.
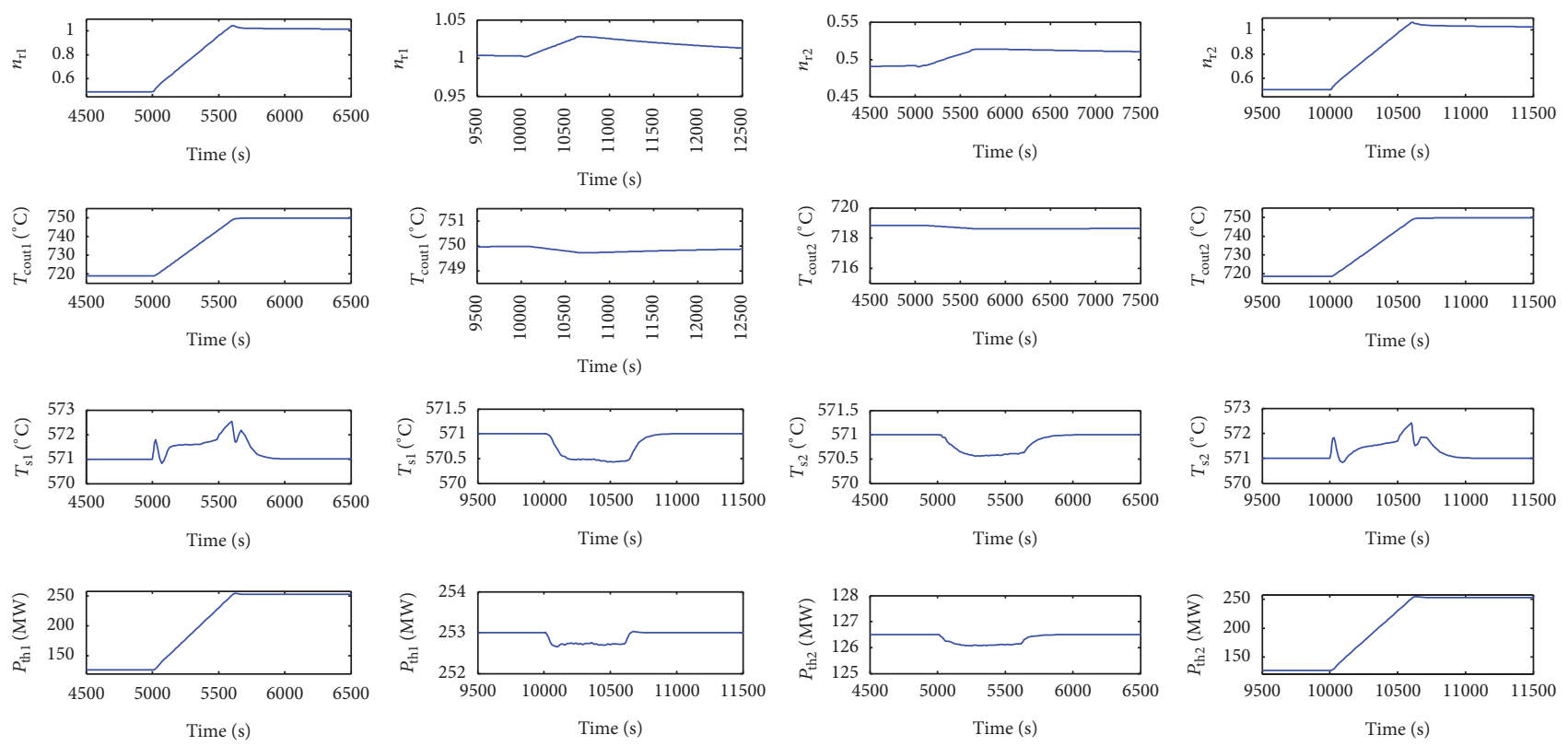

FIGURE 14: Responses of $1 \#$ and 2\# NSSS in the case of power ramp-up: $n_{\mathrm{ri}}, T_{\text {cout } i}, T_{\mathrm{si}}$, and $P_{\mathrm{thi}}$ are, respectively, the relative nuclear power, MHTGR outlet helium temperature, OTSG outlet steam temperature, and total thermal power of the $i$ th NSSS, $i=1,2$.

one NSSS module is in the state of power maneuvering, both the feedwater flowrate and output thermal power of the other NSSS module must vary simultaneously if there is no control input. Due to the proper referenced feedwater flowrates given by thermal power controllers, and due to the effectiveness of the feedwater flowrate control law, both the secondary flowrates and thermal power of the two NSSS modules are statically decoupled with each other, which means that the steady values of the feedwater flowrates (outlet thermal power) of the two NSSS modules are decoupled with each other. For example, from columns 1 and 3 of Figures 8 and 10, the power step of 1\# NSSS module does not influence the steady values of the feedwater flowrate and outlet thermal power of 2 \# NSSS module. Thanks to the plant control strategy proposed in this paper, we can see from the simulation results that the power step and ramp of one NSSS module only induce small transient disturbance to the other module and do not induce steady-point perturbations of the secondary flowrate and thermal power. The feedback laws of the module coordinated control given by (24) and (27) are also simple for engineering implementation and conditioning.

In summary, the power maneuver of the HTR-PM plant can be realized by the plant control strategy given in Section 3 which has already been applied to the HTR-PM power control project. The numerical simulation results show that the HTR-PM plant is flexible enough for constituting HESs with those renewable energy sources such as the wind and 

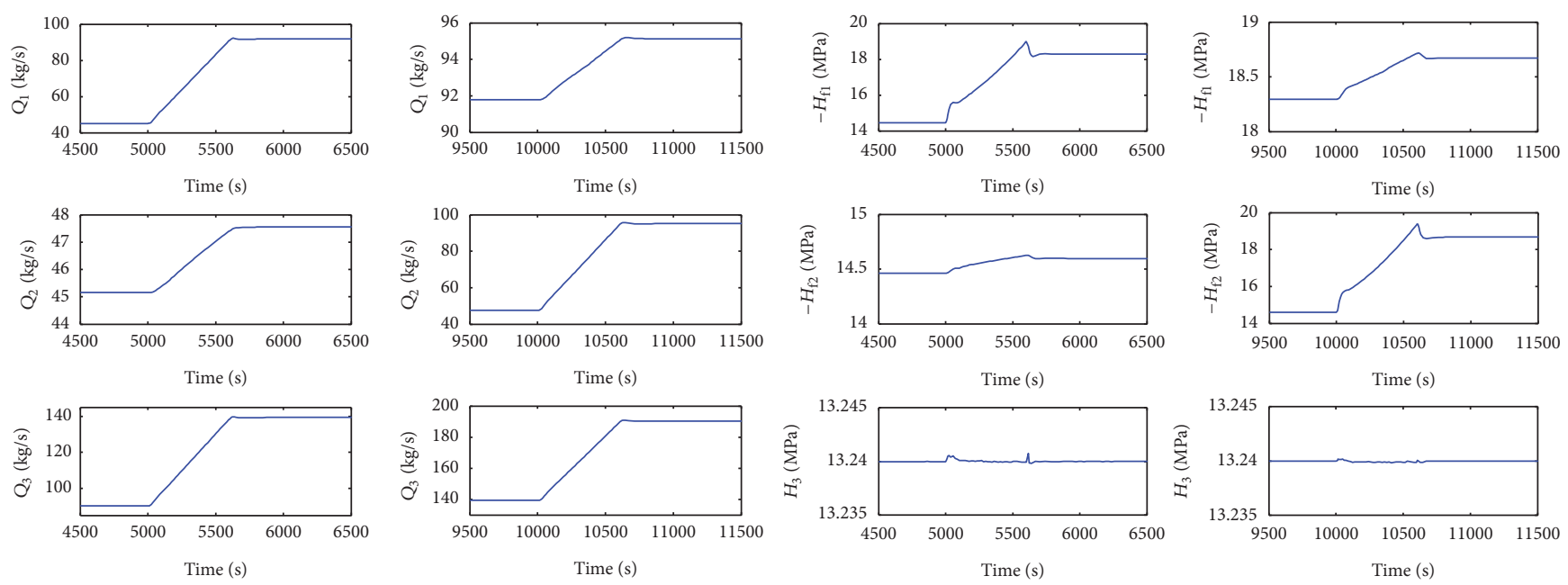

FIGURE 15: Responses of secondary-loop FFN flowrates and pressure drops in the case of power ramp-up.

solar. Moreover, the technical issues of integrating more NSSS modules are nearly the same with integrating two modules by allocating a pump to each NSSS module, implementing module control laws in Section 3.2.2 to each NSSS module and applying module coordination laws in Section 3.2.3 to the secondary FFN.

\section{Conclusions}

Due to its inherent safety feature and potential economic competitiveness, the modular high temperature gas-cooled reactor (MHTGR) has already been seen as one of the best candidates in building the next generation nuclear plants. Through the multimodular scheme, the inherent safety feature of the MHTGR can be applicable to the large-scale nuclear plants at any desired power ratings. Plant power control is the one of the crucial techniques for guaranteeing the safe, stable, and efficient operation of every nuclear plant, and the plant power control strategy of the traditional single-modular nuclear plants cannot be directly applied to multimodular plants. Thus, it is very necessary to study the plant power control of multimodular nuclear plants. Here, dynamic modeling, control strategy design, and performance verification are the three main aspects of plant power control studying, where the former one is the basis for the latter two. In this paper, the dynamical modeling of the main parts of the HTR-PM plant is first given, and the corresponding plant control strategy including the feedback loops and control laws is then proposed. By integrating the dynamic model and power control strategy for a simulation code in MATLAB/Simulink environment, numerical verification is performed. Simulation results in the cases of plant power step and ramp show that the plant control strategy provides satisfactory closed-loop stability and transient performance for the HTR-PM plant. The future work mainly lies in commissioning the power control system of the HTR-PM plant, which is implemented based on the control strategy given in this paper, practically for a practical verification.

\section{Conflicts of Interest}

The authors declare that they have no conflicts of interest.

\section{Acknowledgments}

This work is jointly supported by National S\&T Major Project of China and Natural Science Foundation of China (NSFC) (Grant no. 61374045).

\section{References}

[1] H. E. Garcia, J. Chen, J. S. Kim et al., "Dynamic performance analysis of two regional nuclear hybrid energy systems," Energy, vol. 107, pp. 234-258, 2016.

[2] M. Lykidi and P. Gourdel, "How to manage flexible nuclear power plants in a deregulated electricity market from the point of view of social welfare?” Energy, vol. 85, pp. 167-180, 2015.

[3] W. Dazhong and L. Yingyun, "Roles and prospect of nuclear power in China's energy supply strategy," Nuclear Engineering and Design, vol. 218, no. 1--3, pp. 3-12, 2002.

[4] D. T. Ingersoll, "Deliberately small reactors and the second nuclear era," Progress in Nuclear Energy, vol. 51, no. 4-5, pp. 589603, 2009.

[5] J. Vujić, R. M. Bergmann, R. Škoda, and M. Miletić, "Small modular reactors: simpler, safer, cheaper?" Energy, vol. 45, no. 1, pp. 288-295, 2012.

[6] M. K. Rowinski, T. J. White, and J. Zhao, "Small and medium sized reactors (SMR): a review of technology," Renewable and Sustainable Energy Reviews, vol. 44, pp. 643-656, 2015.

[7] D. D. Lanning, "Modularized high-temperature gas-cooled reactor systems," Nuclear Technology, vol. 88, no. 2, pp. 139-156, 1989.

[8] H. Reutler and G. H. Lohnert, "The modular high-temperature reactor," Nuclear Technology, vol. 62, no. 1, pp. 22-30, 1983.

[9] H. Reutler and G. H. Lohnert, "Advantages of going modular in HTRs," Nuclear Engineering and Design, vol. 78, no. 2, pp. 129136, 1984. 
[10] G. H. Lohnert, "Technical design features and essential safetyrelated properties of the HTR-module," Nuclear Engineering and Design, vol. 121, no. 2, pp. 259-275, 1990.

[11] Z. Wu, D. Lin, and D. Zhong, "The design features of the HTR10," Nuclear Engineering and Design, vol. 218, pp. 25-32, 2002.

[12] S. Hu, X. Liang, and L. Wei, "Commissioning and operation experience and safety experiments on HTR-10," in Proceedings of the 3rd International Topical Meeting on High Temperature Reactor Technology, Johannesburg, South Africa, October, 2006.

[13] Z. Zhang and Y. Sun, "Economic potential of modular reactor nuclear power plants based on the Chinese HTR-PM project," Nuclear Engineering and Design, vol. 237, no. 23, pp. 2265-2274, 2007.

[14] Z. Zhang, Z. Wu, D. Wang et al., "Current status and technical description of Chinese $2 \times 250 \mathrm{MW}_{t h}$ HTR-PM demonstration plant," Nuclear Engineering and Design, vol. 239, no. 7, pp. 12121219, 2009.

[15] G. Y. Han, "A mathematical model for the thermal-hydraulic analysis of nuclear power plants," International Communications in Heat and Mass Transfer, vol. 27, no. 6, pp. 795-805, 2000.

[16] C. Fazekas, G. Szederkényi, and K. M. Hangos, "A simple dynamic model of the primary circuit in VVER plants for controller design purposes," Nuclear Engineering and Design, vol. 237, no. 10, pp. 1071-1087, 2007.

[17] Z. Dong, X. Huang, J. Feng, and L. Zhang, "Dynamic model for control system design and simulation of a low temperature nuclear reactor," Nuclear Engineering and Design, vol. 239, no. 10, pp. 2141-2151, 2009.

[18] R. M. Edwards, K. Y. Lee, and M. A. Schultz, "State feedback assisted classical control: an incremental approach to control modernization of existing and future nuclear reactors and power plants," Nuclear Technology, vol. 92, no. 2, pp. 167-185, 1990.

[19] M. G. Na, I. J. Hwang, and Y. J. Lee, "Design of a fuzzy model predictive power controller for pressurized water reactors," IEEE Transactions on Nuclear Science, vol. 53, no. 3, pp. 15041514, 2006.

[20] G. R. Ansarifar and H. R. Akhavan, "Sliding mode control design for a PWR nuclear reactor using sliding mode observer during load following operation," Annals of Nuclear Energy, vol. 75, pp. 611-619, 2015.

[21] Y. B. Shtessel, "Sliding mode control of the space nuclear reactor system," IEEE Transactions on Aerospace and Electronic Systems, vol. 34, no. 2, pp. 579-589, 1998.

[22] Z. Huang, R. M. Edwards, and K. Y. Lee, "Fuzzy-adapted recursive sliding-mode controller design for a nuclear power plant control," IEEE Transactions on Nuclear Science, vol. 51, no. 1, pp. 256-266, 2004.

[23] H. Li, X. Huang, and L. Zhang, "A simplified mathematical dynamic model of the HTR-10 high temperature gas-cooled reactor with control system design purposes," Annals of Nuclear Energy, vol. 35, no. 9, pp. 1642-1651, 2008.

[24] Z. Dong, X. Huang, and L. Zhang, "A nodal dynamic model for control system design and simulation of an MHTGR core," Nuclear Engineering and Design, vol. 240, no. 5, pp. 1251-1261, 2010.

[25] H. Li, X. Huang, and L. Zhang, "A lumped parameter dynamic model of the helical coiled once-through steam generator with movable boundaries," Nuclear Engineering and Design, vol. 238, no. 7, pp. 1657-1663, 2008.
[26] Z. Dong, "A differential-algebraic model for the once-through steam generator of MHTGR-based multimodular nuclear plants," Mathematical Problems in Engineering, vol. 2015, Article ID 370101, 12 pages, 2015.

[27] Z. Dong, "Self-stability analysis of MHTGRs: a shifted-ectropy based approach," Nuclear Engineering and Design, vol. 248, pp. 137-148, 2012.

[28] Z. Dong, "Dissipation analysis and adaptive control of fluid networks," in Proceedings of the American Control Conference (ACC '15), pp. 671-676, Chicago, Ill, USA, July 2015.

[29] Z. Dong, M. Song, X. Huang, Z. Zhang, and Z. Wu, "Module coordination control of MHTGR-based multi-modular nuclear plants," IEEE Transactions on Nuclear Science, vol. 63, no. 3, pp. 1889-1900, 2016.

[30] Z. Dong, J. Feng, X. Huang, and L. Zhang, "Power-level control of nuclear reactors based on feedback dissipation and backstepping," IEEE Transactions on Nuclear Science, vol. 57, no. 3, pp. 1577-1588, 2010.

[31] Z. Dong, "Nonlinear state-feedback dissipation power level control for nuclear reactors," IEEE Transactions on Nuclear Science, vol. 58, no. 1, pp. 241-257, 2011.

[32] Z. Dong, "Physically-based power-level control for modular high temperature gas-cooled reactors," IEEE Transactions on Nuclear Science, vol. 59, no. 5, pp. 2531-2549, 2012.

[33] Z. Dong, "Power-level control for MHTGRs with time-delay in helium temperature measurement," IEEE Transactions on Nuclear Science, vol. 61, no. 3, pp. 1349-1359, 2014.

[34] Z. Dong, "Model-free power-level control of MHTGRs against input saturation and dead-zone," IEEE Transactions on Nuclear Science, vol. 62, no. 6, pp. 3297-3310, 2015.

[35] Z. Dong, X. Huang, and L. Zhang, "Saturated output feedback dissipation steam temperature control for the OTSG of MHTGRs," IEEE Transactions on Nuclear Science, vol. 58, no. 3, pp. 1277-1289, 2011.

[36] Z. Dong, "Model-free coordinated control for MHTGR-based nuclear steam supply systems," Energies, vol. 9, no. 1, article 37, 2016. 


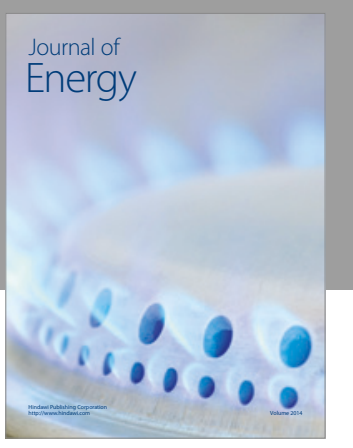

Journal of

Industrial Engineering
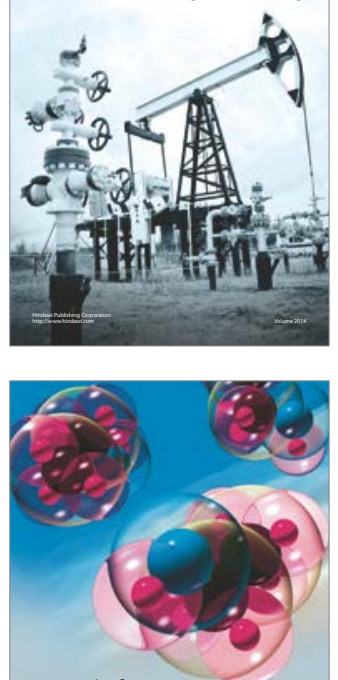

Fuels
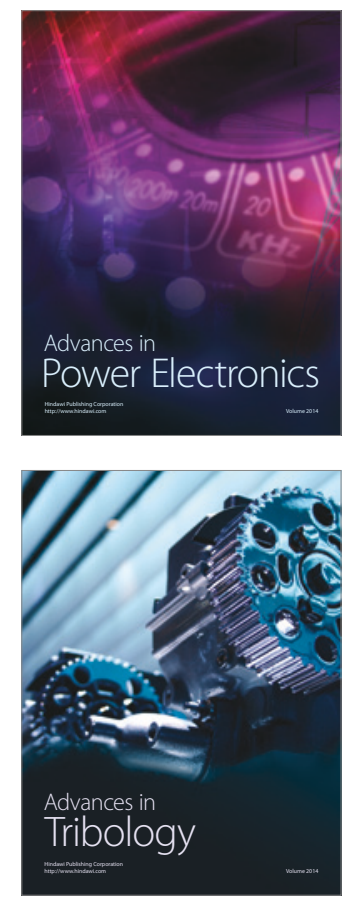
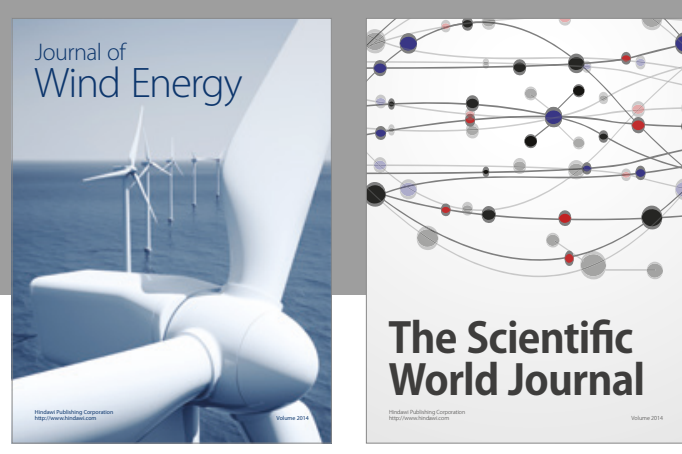

The Scientific World Journal
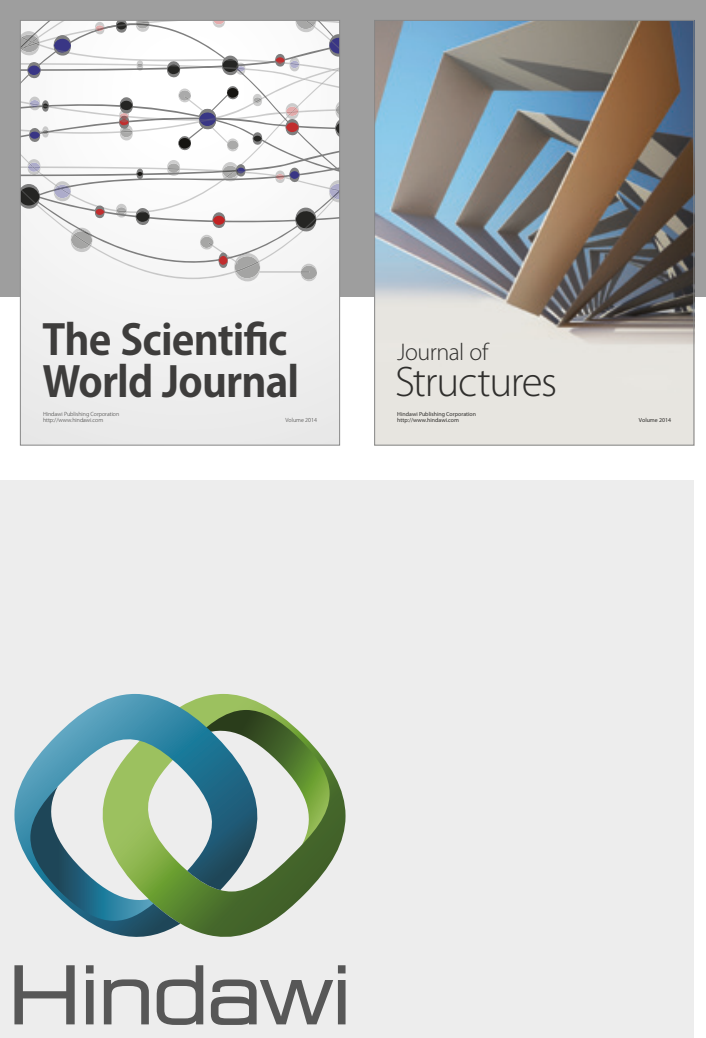

Submit your manuscripts at

https://www.hindawi.com
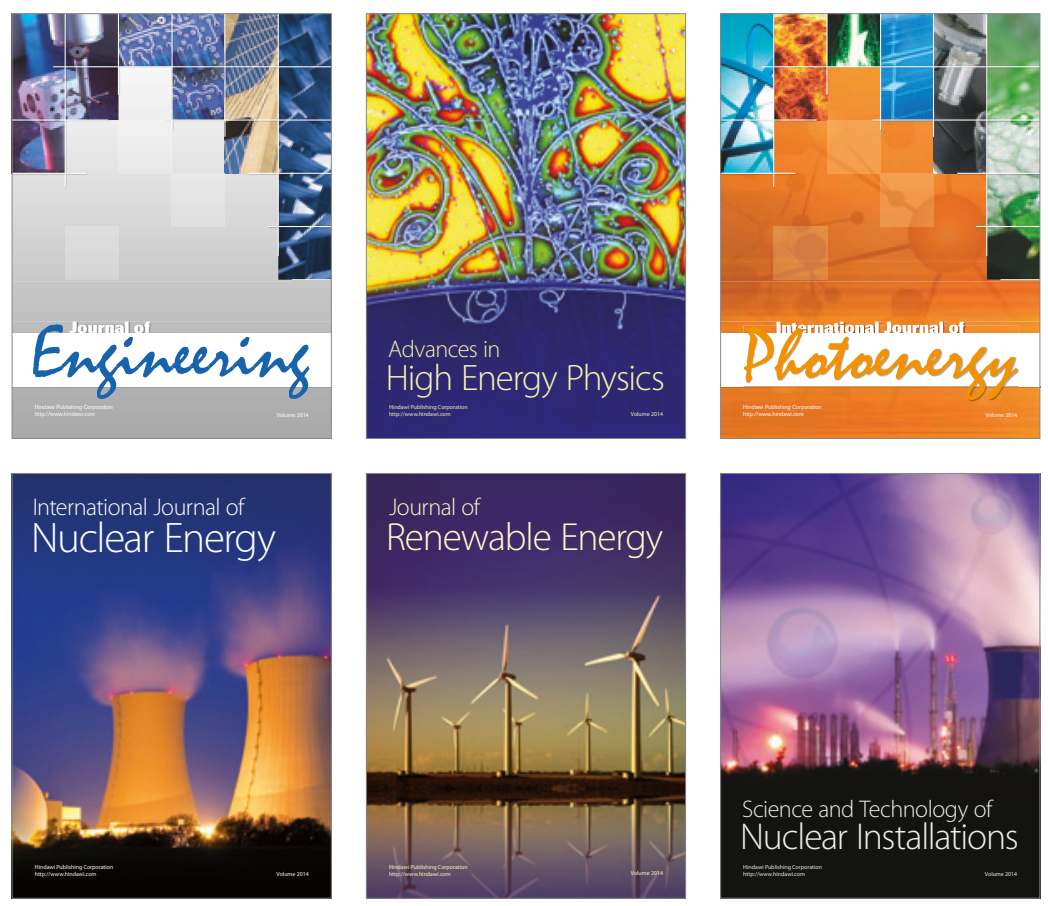

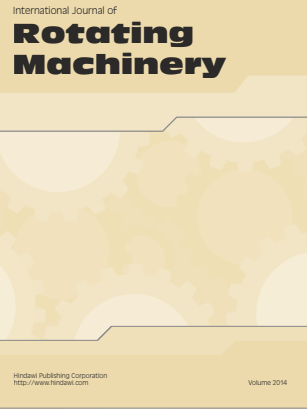

Journal of

Petroleum Engineering

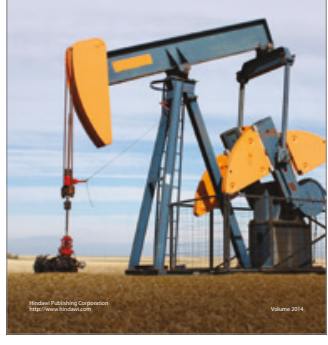

Journal of
Solar Energy
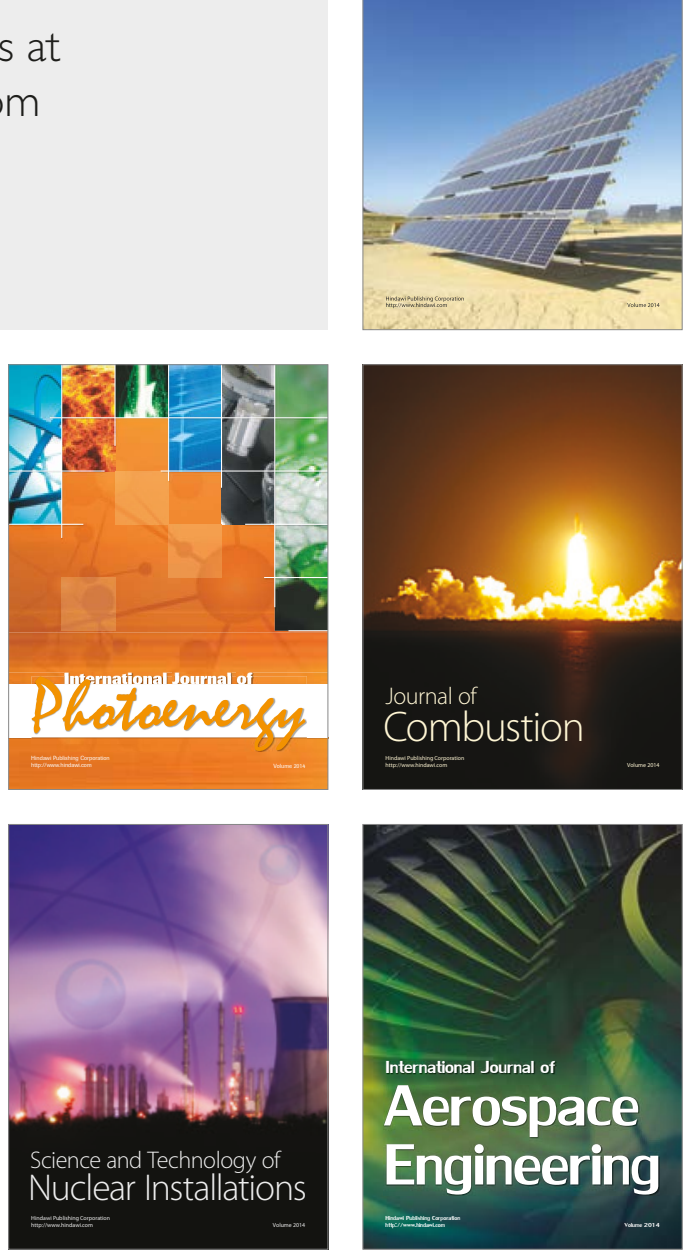